\title{
Risk Assessment in the DOE Assurance Program for Remedial Action
}

\author{
S. Marks \\ F. T. Cross \\ D. H. Denham \\ W. E. Kennedy \\ R. D. Stenner
}

August 1985

Prepared for the U.S. Department of Energy under Contract DE-AC06-76RLO 1830

Pacific Northwest Laboratory Operated for the U.S. Department of Energy by Battelle Memorial Institute 


\title{
DISCLAIMER
}

This report was prepared as an account of work sponsored by an agency of the United States Government. Neither the United States Government nor any agency thereof, nor any of their employees, makes any warranty, express or implied, or assumes any legal liability or responsibility for the accuracy, completeness, or usefulness of any information, apparatus, product, or process disclosed, or represents that its use would not infringe privately owned rights. Reference herein to any specific commercial product, process, or service by trade name, trademark, manufacturer, or otherwise, does not necessarily constitute or imply its endorsement, recommendation, or favoring by the United States Government or any agency thereof. The views and opinions of authors expressed herein do not necessarily state or reflect those of the United States Government or any agency thereof.

\author{
PACIFIC NORTHWEST LABORATORY \\ operated by \\ BATTELLE \\ for the \\ UNITED STATES DEPARTMENT OF ENERGY \\ under Contract DE-AC06-76RLO 1830
}

\begin{tabular}{|c|c|}
\hline \multirow{2}{*}{\multicolumn{2}{|c|}{ Printed in the United States of America }} \\
\hline & \\
\hline \multirow{4}{*}{\multicolumn{2}{|c|}{$\begin{array}{c}\text { National Technical Information Service } \\
\text { United States Department of Commerce } \\
5285 \text { Port Royal Road } \\
\text { Springfield, Virginia } 22161\end{array}$}} \\
\hline & \\
\hline & \\
\hline & \\
\hline \multirow{2}{*}{\multicolumn{2}{|c|}{$\begin{array}{l}\text { NTIS Price Codes } \\
\text { Microfiche A01 }\end{array}$}} \\
\hline & \\
\hline \multicolumn{2}{|c|}{ Printed Copy } \\
\hline & Price \\
\hline rages & \\
\hline $001-025$ & A02 \\
\hline 026-050 & $\mathrm{A} 03$ \\
\hline 051-075 & A04 \\
\hline 076-100 & A0S \\
\hline $101-125$ & A06 \\
\hline $126-150$ & $A 07$ \\
\hline $151-175$ & $A 08$ \\
\hline $176-200$ & $\wedge 09$ \\
\hline $201-225$ & A010 \\
\hline $226-250$ & A011 \\
\hline $251-275$ & A012 \\
\hline 276-300 & $\wedge 013$ \\
\hline
\end{tabular}


RISK ASSESSMENT IN THE

DOE ASSURANCE PROGRAM

FOR REMEDIAL ACTION

S. Marks

F. T. Cross

D. H. Denham

W. E. Kennedy

R. D. Stenner

August 1985

Prepared for

the U.S. Department of Energy

under Contract DE-AC06-76RLO 1830

Pacific Northwest Laboratory

Richland, Washington 99352 
•

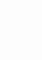




\section{ABSTRACT}

This document provides information obtained during the performance of several risk assessment tasks in support of the Assurance Program for Remedial Action (APRA) sponsored by the Office of Operational Safety of the Department of Energy. We have presented a method in this project for the estimation of projected health effects at properties in the vicinity of uranium mill tailing piles due to transported tailings or emissions from the piles. Because radon and radon daughter exposure is identified as the principal factor contributing to heal th effects at such properties, the basis for estimating lung cancer risk as a result of such exposure is discussed in detail. Modeling of health risk due to a secondary pathway, ingestion of contaminated, home-grown food products, is also discussed since it is a potentially important additional source of exposure in certain geographic locations. Risk assessment methods used in various mill tailings reports are reviewed. The protocols for radiological surveys conducted in DOE-sponsored remedial action programs are critically reviewed with respect to their relevance to the needs of health risk estimation. The relevance of risk assessment to the APRA program is discussed briefly. 
- 


\section{ACKNOWLEDGMENTS}

We wish to acknowledge the valuable participation in the past of additional PNL staff members, principally K. A. Hawley and R. E. Jaquish, in the work that forms the basis for this document. L. F. Anderson and G. R. Ripley of the State of Utah Department of Health contributed information on the occupancy of properties vital to the calculation of risk estimates for Salt Lake City vicinity properties. B. A. Berven, Oak Ridge National Laboratory, and P. H. Jenkins, Monsanto Research Corporation, generously provided necessary survey reports upon request. Above all, we are grateful for the vitally important support of C. G. Welty, Jr., T. S. Needels and W. E. Mott of the Office of Operational Safety of the Department of Energy, who initiated and encouraged the development of the studies upon which this document is based. 
. 


\section{CONTENTS}

OVERVIEW . . . . . . . . . . . . . . . ....

Introduction ......................

Source Term . . . . . . . . . . . . . . . . . .

Occupancy . . . . . . . . . . . . . . . . . . .

Risk Estimation......................

Relevance of Risk Assessment ...............

METHOD FOR THE ESTIMATION OF RADIOLOGICAL HEALTH EFFECTS AT

URANIUM MILL TAILINGS VICINITY PROPERTIES . . . . . . . . . . 5

Introduction .......................

Measurement Data . . . . . . . . . . . . . . .

Estimation of Risk and Health Effects...........

Summary . . . . . . . . . . . . . . . . . . .

References

RISK OF LUNG CANCER FROM RADON (RADON DAUGHTER) EXPOSURES . . .

Introduction . . . . . . . . . . . . . . . . . . . .

Lung Dosimetry Models . . . . . . . . . . . . . . .

Radon Daughter Epidemiology Studies... . . . . . . .

Animal Studies

Lung Cancer Risk Prediction Model . . . . . . . . . . .

References

INGESTION DOSE MODELS . . . . . . . . . . . . . .

A REVIEW OF RADIOLOGICAL RISK ASSESSMENT METHODOLOGIES FOR

URANIUM MILL TAILINGS PILES AND VICINITY PROPERTIES . . . . . . .

Introduction . . . . . . . . . . . . . . . . . . . .

Radiological Assessment Methodology of ORNL B. - . Dais

Utah, Inc.

Radiological Assessment Methodology of Sandia National

Laboratories .......................

Summary..........................

Additional References

REVIEW OF RADIOLOGICAL SURVEY TECHNIQUES USED IN DOE REMEOIAL

ACTION PROGRAMS FROM THE STANOPOINT OF RISK ASSESSMENT . : . . . . Introduction and Scope . . . . . . . . . . . . . . . DOE Remedial Action Program Survey Protocols ........ Survey Data and Risk Assessments . . . . . . . . . . . Recommendations and Conclusions............. References

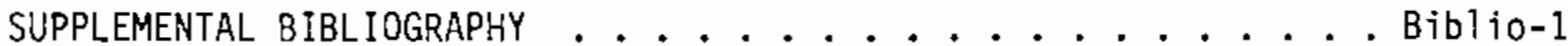




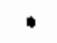

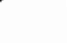


CHAPTER 1

OVERVIEW

INTRODUCTION

This document represents a synthesis of work conducted to date on risk assessment at the Pacific Northwest Laboratory (PML) in support of the U. S. Department of Energy (OOE) Assurance Program for Remedial Action (APRA). The program is sponsored by the DOE Office of Operational Safety. ,

The document includes a presentation of a method deveioped by PNL for the estimation of risk and heaith effects at vicinity properties in the Uranium Mill Tailings Remedial Action Program (UMTRAP). In support of the method, chapters are included that describe the risk of lung cancer from radon (radon daughter) exposures and the use of ingestion dose models. An additional major segment of the document is concerned with the review of procedures employed by other organizations. These include a chapter concerned with the risk assessment methods used by other contractors and a chapter on the review of radiological survey techniques, viewed from the standpoint of risk assessment.

\section{SOURCE TERM}

The first step in the estimation of risk is the characterization of the source term for the exposure of persons potentially at risk. The radiological characterization that provides the source-term data is usually a multipurpose activity. Surveys are conducted to confirm suspected radiological contamination at levels above background such that they are potential candidates for remedial action. They are designed to provide a basis for compliance with standards. The surveys also address engineering needs in projecting the nature of the remedial action that will be required. Satisfying needs for risk assessment appears to have been a Tesser consideration in conducting the radiological surveys. The relevance of data collected in the radiological surveys to risk assessment are addressed in the discussion of the methods developed for estimating health effects (Chapter 2) and in the review of radiological surveys from the standpoint of risk assessment (Chapter 6 ). 
OCCUPANCY

The source term described above provides data concerning the leveis of exposure of various types that persons are likely to encounter. In addressing the relative need for a remedial action to be taken, the potential impact on exposed individuals is an important consideration: Exposure will create a risk to individuals, which may or may not be considered reasonable or acceptable. In addition, the aggregate effect is important in that the exposure of substantial numbers of persons may warrant greater urgency in instituting a remedial action than would be the case if the same level of exposure were experienced in an occasional isolated manner. In the case of vicinity properties, we will see that occupancy is important not only in defining the number of individuals likely to be exposed in a given property but also the numbers that are apt to be exposed to different levels of the radiation sources in different indoor locations.

\section{RISK ESTIMATION}

The objectives in risk estimation are largely independent of the type of property that serves as a site of exposure. For example, whether the site being evaluated is a formerly utilized site, a uranium mill tailings pite or a vicinity property contaminated with tailings, the assessment of risk involves the calculation of the health risk to an individual resulting from exposure to a given source. A second measure of risk is provided by the increase in that risk over a comparable normally occurring risk, such as the increased probability of cancer expressed as a percentage of the individual's normal risk of developing cancer or the specific cancer type. Finally, the risk associated with a given source must be evaluated in terms of the magnitude of the effects that may be caused by the exposure. In the case of tailings piles, this may involve exposure of populations surrounding or downwind from the pile. A vicinity property may be commercial or residential, resulting in different patterns of exposure and duration of exposure for occupants. Furthermore, the distribution of individuals within a property and the Teve? of occupancy may influence the number of projected induced effects. 
The spectrum of exposures creates a demand for risk coefficients that enable the investigator to calculate risk related to exposure level, based on current best information. Accepted risk coefficients for ganma-ray exposure are relatively simple. On the other hand, the risk coefficients for inhaled radon and its daughters are quite complex and are addressed in Chapter 3 of this document. Radionuclides ingested by the food pathway also require relatively elaborate models for the calculation of their associated risk. Models for the food pathway are treated in Chapter 4.

Finally, the risk assessment methods employed by other organizations are reviewed in detail in Chapter 5 of this document.

\section{RELEVANCE OF RISK ASSESSMENT}

Risk assessment has assumed increasing importance in recent years. Several purposes may be served by the assessment of risk as described here. A paramount consideration is the establishment of priorities in authorizing remedial actions. The duration of the remedial action program as authorized by the Congress and the annual rate of funding of the program may be such that not all actions considered desirable or required to comply with standards will be accomplished. This circumstance imposes on the Department of Energy a need to establish priorities in performing $i$ ts remedial actions. As 1990 (the end of the authorization period) approaches, if a review of the program discloses that low-priority properties or sites will have been decontaminated while higher-priority examples remain untouched, the effectiveness of the overall program will be seriously questioned. Estimation of individual risk and of projected health effects in relation to cost of a remedial action is probably the most relevant means for justifying the priority assigned to a given action.

Standards promulgated by such cognizant agencies as the Environmental Protection Agency (EPA) are subject to periodic review. In the case of remedial action programs, the organization most concerned and best equipped to provide such review, comment and suggestion concerning relevant standards is the Department of Energy. The basis for such a review must be prepared well in advance. A remedial action program that is geared solely 
to comply with standards will not provide an informed basis for review and recommendation. The cost-benefit contribution of a risk-assessment component of the program will permit an enlightened approach to any future evaluation of the propriety of existing standards.

A further application of risk assessment lies in the surveillarice of DOE programs by individual congressmen or congressiona? committees. In the past, a key question that has been raised by congressmen relative to facilities in their districts that fall within the scope of UMTRAP or FUSRAP programs has been the risk to persons from residual contamination. Another issue raised in congressional hearings is the cost-effectiveness of the remedial action programs. Finally, the utilization of risk assessment and evaluation by government departments and agencies has become a sufficient congressional concern to warrant passage of H.R. 4192, "The Risk Assessment Research and Demonstration Act of 1983." Pursuant to this Act, Hon. James H. Scheuer, Chaiman, Subcommittee on Natural Resources, Agriculture Research and Environment of the Committee on Science and Technology of the U.S. House of Representatives requested of Secretary Paul Hodel on Aprit 23, 1984 written responses to questions concerning risk assessment activities required of the Department under H.R. 4192. The latter action illustrates the level of congressional interest in the application of risk assessment and evaluation to major programs authorized by the U.S. Congress.

In summary, an effective risk assessment program provides (1) a rational basis for establishing priorities in the conduct of a remedial action program; (2) the means to provide informed comment and suggestion in the periodic review of relevant standards; and (3) data required to satisfy congressional inquiry of the Department as well as the mandated need to include such an activity in carrying out its authorized functions. 
CHAPTER 2

\begin{abstract}
METHOD FOR THE ESTIMATION OF RADIOLOGICAL HEALTH EFFECTS AT URANIUM MILL TAILINGS VICINITY PROPERTIES
\end{abstract}

\title{
INTRODUCTION
}

This chapter is concerned with the estimation of heal th effects at vicinity properties contaminated with tailings transported from a uranium mill tailings pile or located sufficiently near a pile to be affected by it. The principal objectives of the approach adopted here are to provide best estimates of cancer risk to exposed individuals and of projected numbers of cancer deaths based on occupancy and the pattern of contamination in individual properties. Although the methods were developed to provide estimates for Salt Lake City properties, the approach should be applicable to other sites, subject to the modification of details to account for individual site and property characteristics.

The principal factor in health risk for properties containing tailings beneath structures is usually radon (Rn-222) and its daughters. The other factor in the structures is the ganma-ray exposure. Tailings in soir surrounding structures may contribute gamma-ray exposure and, in the case of residences, Ra-226 exposure (deposited internally in the body) via the food chain.

Because estimates of heaith risk and events are contingent on measurements of exposure values, the quality of the estimates depends upon the availability of appropriate measurement data. The latter are provided by radiological surveys that may serve purposes other than health-risk estimation. In fact, the thrust of the surveys in DOE remedial action programs appears to have been directed toward compliance with standards and guidelines. Therefore, the following discussion will consider the estimation process in light of the data that have been available to us for properties in the Salt Lake City area. 
MEASUREMENT DATA

The measurement data in the radiological survey reports that were available comprised both indoor and outdoor measurements (see Chapter 6); the values in the survey reports included background. The indoor measurements included direct and transferable surface alpha and beta-gamma measurements. External gamma-ray measurements were taken either at grid points or in the center of a room if not large, both at the floor surface and at a level $1 \mathrm{~m}$ above the floor. Radon and daughter measurements were made only indoors and were undertaken onty if elevated gamma-ray levels were observed. The minimal measurements in this respect were made on grab radon samples. At the next level, grab radon and daughter samples were measured. If indicated by the results of grab sample measurements, continuous radon measurements were made over a period of several days by means of a Wrenn chamber (providing hourly radon averages), and/or PERM measurements were obtained for a period of four or five weeks.

Outdoor measurements were directed to external gama-ray exposure and soil concentrations of radionuclides, principally Ra-226 and U-238 and, occasionaliy, Th-232. The gamma readings were obtained at grid points at ground level and $1 \mathrm{~m}$ above ground. Soil samples were obtained either at grid points or at locations having elevated gamma-ray measurement values. The samples were obtained from auger holes and usually included both surface (< $15 \mathrm{~cm}$ below the surface) and subsurface ( $\geq 15 \mathrm{~cm}$ below the surface) soil, identified separately. Groundwater samples were also analyzed when indicated (ORNL 1982).

The most relevant measurements for health-effect estimation are the indoor external gamma values at $1 \mathrm{~m}$, the indoor radon gas and daughter values, and the weighted-average soil radionuclide concentrations (for residences). The outdoor external gamma levels and soil concentration values provide a perspective on the distribution of contamination with respect to a structure, its constituent parts, and the surrounding land. When exposures in a structure are too low to permit the calculation of 
positive risk estimates in residential structures, risk and health effects based on outdoor ganma measurements are calculated.

\section{ESTIMATION OF RISK ANO HEALTH EFFECTS}

Three measures of risk and health effects are recommended. All relate to exposure above background, which imposes the requirement that background values be subtracted from measured or estimated exposure vaiues. The first is the lifetime cancer risk to the individual; the second, the percentage increase in the individual's cancer risk relative to the noma? cancer risk in the U.S. population; and the third, the number of excess cancer deaths during a lifetime or 50-year period, based on occupancy of the structure or site and exposure encountered at different locations in the structure. The third is the most important of the three measures for the purpose of setting priorities for remedial action and for comparing the cost-effectiveness of remedial action undertaken with respect to mill tailings with that of remedial or preventive actions instituted for other potential health hazards. This type of estimate lends itself to a cost-benefit approach in providing data suitable for the calculation of the cost per death prevented.

Best estimates rather than maximal estimates are caiculated because health-effect estimates, based on maximal measurement values, when applied to an entire property, can drastically distort the probability of calculated events. A maximat value that approximates the average throughout a property in the presence of uniform distribution of contamination may be considered reasonably representative. On the other hand, a high value due to a limited pocket of contamination when all or most other measurements have substantially lower values, reflecting little contamination in those areas, would produce a distorted picture. The maximal values for the two properties could be equal, while the anticipated health conseouences are actually very different. Furthermore, a maximal value may be an outlier, resulting from measurement error or random variation, rather than a higher level of contamination. For these reasons, best estimates are preferred to estimates based on maximal values. 
As stated above, in our health-effect calculations, we have used gamma radiation exposure rates, radon gas or daughter concentrations, and weighted-average soil concentrations (at residential properties). The gamma measurements are relatively straightforward. External gamma measurement values at $1 \mathrm{~m}$ abcve the surface (or at the surface if not available at $1 \mathrm{~m})$ are most appropriate for this purpose. In the absence-of information to the effect that work at commercial properties is performed outdoors, one may limit consideration of gamma-ray measurements to indoor values. For residences, the time that we have allotted for indoor occupancy $(7000 \mathrm{~h})$ is considered sufficiently conservative to also account for gama-ray exposure during the more limited time likely to be spent outdoors. However, in cases where indoor exposure does not exceed the background level, outdoor exposure to gama radiation for $500 \mathrm{~h} / \mathrm{yr}$ may be assumed. The principal problem here is one of relating the measured levels to the exposure of occupants, that is, whether to average over an entire structure, individual rooms, or sets of rooms having relatively uniform levels. The extreme variation in gamma levels in a given building may influence the estimate of projected cancer deaths if occupancy is not uniform with respect to the data points. In most structures, the cancer risk due to gamma exposure is sma11 in comparison with that due to radon daughters. However, the greater duration of exposure of occupants of residences when compared with commercial buildings may increase the risk from gamma exposure to levels warranting attention (if not overshadowed by simultaneous radon daughter exposures).

Estimation of radon gas and/or daughter exposures and associated equilibrium factors is a much more difficult task. The need for the estimation of working level values for radon daughters is obvious. The need for estimates of equilibrium factors is less so. However, the equilibrium factor allows the estimation of a working level value from radon gas concentrations, which is essential if daughter values are not available or is preferred if the daughter measurements are less valid or representative than the available radon gas measurements. In addition, the cancer risk for the individual with a given exposure in terms of working leve? 
months (WLM) ${ }^{(a)}$ per year varies with the disequilibrium of the daughters and, therefore, indirectly with the equilibrium factor. Risk coefficients appropriate to different values of the equilibrium factor have been developed (see discussion in Chapter 3 ) and are used in our calculation of lung cancer risk estimates. In contrast to the abundance of reliable gamma-ray measurements, the radon gas and/or daughter measurements are sparse and, often, unreliable. The reasons of complexity, cost and inaccuracy of measurement, and variability of concentrations due to diurnal, seasonal and temporary environmental conditions (such as opening of doors or windows, operation of ventilation equipment, etc.) are too well documented to warrant discussion here.

Grab radon or daughter measurements are frequently not representative of the individual's exposure throughout either the work or "at home" day because of the variation in measurement values during the period and the influence of temporary conditions. However, grab values of necessity are used in calculations when integrated or continuous measurements are not, available. If both radon gas and daughter grab sample values are provided and are presumed to be of equal merit, the daughter values are to be preferred. Means of long-term radon gas measurements are generally accepted over grab radon daughter and, certainly, over grab radon gas measurements. Integrated or continuous measurements improve the prospect that the measurements obtained will be representative of the long-term average conditions. However, the use of a gas concentration value does introduce an element of uncertainty in requiring the use of an equilibrium factor. If suitable correction factors are available, an attempt should be made to correct for diurnal or seasonal variation.

Estimates of the equilibrium factor are calculated from simultaneous measurements of the gas and daughters when available, it is hoped, under

\footnotetext{
(a) A working level (WL) is defined as a concentration of short-lived radon daughters (i.e. RaA, RaB, RaC and RaC') totaling $1.3 \times 10^{5}$ MeV of potential alpha energy per liter of air. A working level month (HLM) is an exposure equivalent to $1 \mathrm{WL}$ for $170 \mathrm{~h}$.
} 
conditions that are typical of the exposure of occupants. An arbitrary equilibrium factor of 0.3 , called the default factor, is used in cases when data suitable for the calculation of an appropriate factor are not available. The assumed equilibrium factor of 0.3 is based on values calculated earlier in Salt Lake City (EPA 1974) and on data obtained in Edgemort, South Dakota and in other countries such as the Federal Republic of Germany. Guidelines for acceptance on a case-by-case basis of radon, radon daughter and equilibrium factor estimates are listed below. We should clarify that acceptance as a best available estimate does not imply a uniform level of confidence in the validity of the accepted values, some of which may be based on scanty data. Obviously, only a few measurements are made at times during surveys because the levels are considered too low to justify the additional expense involved in accumilating more satisfactory data.

The guidelines that we have employed are as follows:

1. If only grab radon measurements are available, use them with the default equilibrium factor of $D .3$ to calculate the radon daughter working level unless available data indicate that another equilibrium factor value is more appropriate.

2. Use grab, integrated or continuous radon gas and radon daughter values to calculate an equilibrium factor if the measurements are simultaneous, overlap or near each other in time unless values are not reasonable or measurement conditions are considered abnormal on the basis of available information.

3. If grab radon and radon progeny measurements are available, use grab radon progeny values unless radon gas measurements are more adequate.

4. If grab radon and/or grab radon daughter and integrated or continuous radon measurements are available, use integrated or continuous radon measurements with an appropriate equilibrium factor uniess radon progeny data are of sufficient quality to be used directly. 
As discussed above, the principal alternatives in measuring health impact from the radiation exposure of persons occupying the properties are the risk to the individual in absolute terms, the relationship of that risk to the normal probability of developing cancer or a particular cancer type in the United States or the local population, and the total risk to the occupants of a property. It is conceivable that, in rare instances, the estimated probability of cancer deveiopment in an individual or a few persons may be unacceptably high. This may be the case in spite of the small number of exposed individuals and, perhaps, the lesser total of projected cancer deaths when compared with another property of comparable cleanup cost. However, in general, we consider the total number of projected deaths for a property and its potential cost-benefit implications to be a more satisfactory means of measuring relative harm. That is the reason for stressing the importance of adequate occupancy data, which may permit the distribution of persons or work-hours in areas of a structure having different exposure levels such that full-time annual equivalents of specific exposure can be estimated.

We have referred to the relationship of the risk of cancer in exposed individuals to their normal probability of developing cancer. The relationship is expressed as the percentage of increase in the individual's risk. The term "normal risk" here refers to cancer deaths from all causes as reported in U.S. vital statistics. In a technica? sense, factors that may be considered "abnormal," such as cigarette smoking and exposure to chemicals, also contribute to cancer mortality. However, we use the term norma 1 to refer to the total cancer or lung cancer risk other than that due to the exposures under consideration. The percentage of increased risk due to gamma rays is based on the value of 0.164 for normal cancer risk as used in the BEIR-3 report for the lifetime age and sex composition of the population of the United States. The percent increase in radon daughter risk is based on a lifetime U.S. lung cancer risk of 0.041 .

The radiation exposures considered here are arbitrarily assumed to exist for a 50-year period. The selection of 50 years is somewhat arbitrary but is likely to be compatible with the expected iife span of a person of average age in the U.S. population and also accommodates the 
latency period in cancer induction. It may also constitute a reasonable expectation for the remaining life span of a building. In any event, adjustments in the number of estimated health effects may be made easily for other arbitrarily selected periods of exposure.

Projected cancer deaths due to gamma rays, radon daughters and radionuclides in the food chain from home gardens are based on the number of annual-equivalent persons exposed to a specified level. Use of the linear hypothesis is implicit in this estimation process in that the duration of individual occupancy is irrelevant to the risk calculations. If, for example, the occupancy for a property is five annual-equivalent persons, the number of cancer deaths is assumed to be the same, whether one or ten persons fill a given occupancy slot over a 50-year period. The linear hypothesis may be challenged as unduly conservative for gamma radiation but is generally used in applications of this kind. The linear hypothesis is widely accepted as appropriate for radon daughters.

As indicated above, exposure levels above background for ganma radiation, radon daughter and food pathway exposure are considered most appropriate for calculations of excess risk and health-effect estimation. In our own estimation process we have used background levels developed by ORNL, e.g., $8 \mu R / h$ for gamma-ray exposure in nonmasonry buildings, $0.007 \mathrm{WL}$ for radon daughters on first-floor levels (0.013 WL for basements), and 1.5 $\mathrm{pCi} / \mathrm{g}$ for Ra-226 concentration in soil. Site-specific background data, if available, would be preferred.

The gamma background value may be modified to reflect the influence of building materials. An alternative mean background value may be calculated for parts of a structure that have no apparent relationship to contaminated materials when an adjustment is warranted by the nature of the building materials. There is sufficient evidence from other studies and in our own data set to justify raising the background value to a level as high as 12 $\mu R / h$ or, perhaps, even slightly higher in buildings of concrete, stone or brick construction. 
In calculating health effects, we have used a lifetime risk coefficient of $10^{-4}$ cancer deaths per rem of gamma-ray exposure (UNSCEAR 1977). The lifetime lung cancer risk for exposure to radon daughters is based upon coefficients derived from underground miner data for lifetime mortality of lung cancer per rad exposure to radon daughters. The values of the coefficients depend upon certain relevant factors as developed in the report of the Task Group for Radon and Daughters of NCRP Scientific Committee 57 for Internal Emitter Standards (NCRP 1984) and in Chapter 3 of this document. The coefficients, derived from uranium miner exposures, are adjusted for the rad per WLM environmental exposure at a given value of the eauilibrium factor and the WLM per year for the observed environmental WL concentration (minus background). The coefficients for lung cancer mortality assume that the stated annual exposure occurs throughout the 1 ifetime of a person of average age. For these reasons, a single value for the risk coefficient is not appropriate. The risk coefficients for both gamma-ray and radon daughter exposure differ between commercial and residential properties because of the expected duration of exposure. The standard value for the number of hours of a worker's exposure is 2000 per year. An occupant of a residence is considered to be exposed for about $80 \%$ of his time (7000 hours). The number of projected cancer deaths due to gamma-ray and lung cancer deaths due to radon daughter exposure is based on the numbers of occupants exposed in different areas in a structure.

At residential sites, ingestion of garden crops, assumed to be grown on the property, is included as a potentiat exposure pathway. For these calculations, the individuals occupying residential properties are assumed to ingest $10 \%$ of the fruit and vegetable segment of their diet from the backyard garden. In the special case of Salt Lake City, the proportion of the fruit and vegetable segment of the diet produced in a home garden is increased to $50 \%$ because of ethnic living patterns. The diet itself is assumed to be average rather than maximal in accordance with the approach adopted here. The transfer of radionuclides to the garden crops is assumed to arise from the surface $(0-15 \mathrm{~cm})$ soil layer. Unless special considerations, such as a fenced garden, warrant selection of a limited area for the site of crop cultivation, the entire back and side yards are assumed to be equally likely locations for planting. The soil concentrations at sam- 
ple sites, the estimated extent of contaminated areas and an estimate of the total area available for cultivation are used to calculate the weightedaverage soil concentration. This concentration is used in the computer code PABLM for estimating dose to man from food products grown in contaminated soir as described in Chapter 4.

Examples of complete and abbreviated property reports are appended to this discussion.

\section{SUMMARY}

We have described an approach to the estimation of individual risk and projected health effects for uranium mill tailing vicinity properties. In the properties reviewed to date, exposure to occupants resulted from radon and its daughters indoors, external gamma rays both indoors and outdoors, and radionuclides in the soil by way of the food chain. The radon daughter exposure is usually the most important of the sources in causing health effects. We have indicated the types of measurements that are available from radiological surveys and described briefly criteria for selection from among available radon and daughter data for use in calculations. The methods and assumptions employed in calculating individual risk, percentage increase in risk over so-called nomai risk, and the estimated health effects for a given property are also presented.

\section{REFERENCES}

EPA 1974. Environmental Surveys of the Uranium Mill Tailings Pile and Surrounding Areas, Salt Lake City. EPA-520/6-74-006, U. S. Environmentai Protection Agency, Las Vegas, Nevada.

NCRP 1984. Evaluation of Occupational and Environmental Exposures to Radon and Radon Daughters in the United States, Report No. 78. National Council on Radiation Protection and Measurement, Bethesda, MD. 
ORNL 1982. Procedures Manual for the ORNL Remedial Action Survey and Certification Activities (RASCA) Program. ORNL/TM-8600, Oak Ridge NationaT Laboratory, Oak Ridge, TN.

UNSCEAR 1977. Sources and Effects of Ionizing Radiation. United Nations Scientific Committee on the Effects of Atomic Radiation. United Nations, New York, NY. 
CHAPTER 3

RISK OF LUNG CANCER FROM RADON (RAOON DAUGHTER) EXPOSURES

INTROOUCIION

Bale (1951) and Harley (1953) were the first to point out that the lung cancer hazard from exposure to radon and radon daughters was not from the radon per se but rather from the alpha dose delivered through lung deposition of the short-Tived daughters of radon $\left[{ }^{218} \mathrm{Po}(\mathrm{RaA})\right.$, ${ }^{214} \mathrm{~Pb}(\mathrm{RaB}),{ }^{214} \mathrm{Bi}(\mathrm{RaC})$ and $\left.{ }^{214} \mathrm{Po}\left(\mathrm{RaC}^{\prime}\right)\right]$. Two alpha emitters, ${ }^{218} \mathrm{Po}(\mathrm{RaA})$ and ${ }^{214} \mathrm{Po}_{\mathrm{O}}\left(\mathrm{RaC}^{\prime}\right)$, ultimateiy deliver the carcinogenic dose to tracheobronchial epithelium. The complexity of the dose estimates (reouired to account for daughter deposition, radioactive buildup and decay, removal by physiologic clearance processes, and physical dose calculations to specific celis in bronchial mucosa) has been detailed by a large number of authors and has been considered by various national and internationa? organizations (see Altshuler, Nelson and Kuschner 1964; FRC 1967; Fry 1977; Haque 1966, 1967; Haque and Collinson 1967; Harley and Pasternack 1972, 1981; Hofmann 1982; Jacobi 1964, 1972, 1977; ICRP 1977, 1981; Jacobi and Eisfeld 1980; James, Greenlhalgh and Birchall 1980; James, Jacobi and Steinhausler 1981; JCAE 1967, 1969; McPherson 1979; NAS 1972, 1980; NCRP 1984; Nelson et al. 1974; NIOSH/NIEHS 1971; Parker 1969; Walsh 1970, 1971, 1979; UNSCEAR 1972, 1977; USPHS 1957, 1961; Wise 1982).

Historically, exposure is defined in terms of the air concentration of radon daughters in working level ( $W L$ ) and working level month (WLM) units. The definitions of WL and WLM on page 2-5 avoid the problems of disequilibrium of the daughters, and also that of whether the daughters are attached to a carrier aerosol or are unattached. Attached radon daughters deposit with some finite probability on the lung surfaces, whereas unattached radon daughters deposit in the respiratory tract with nearly $100 \%$ probability. Thus, the mix of attached and unattached radon daughters is an important consideration in assessing lung dosinetry. 
Fortunately, the unattachment fraction values found in the workplace (and in the environment) are reasonably constant and are sufficiently similar so that they do not cause a large disparity in the radiological dose assessment of environmental and occupational exposures to radon daughters. The same can be said for the other parameters influencing radon daughter lung dose, such as differences in daughter product equilibrium, particie size distributions, breathing patterns, bronchial morphometry and physiological clearance processes.

\section{LUNG DOSIMETRY MODELS}

The more recent radon daughter lung dosimetry models, which are in substantial agreement with one another, place the bronchial epithelium exposure-to-dose conversion factor at about $0.5 \mathrm{rad} / \mathrm{WLM}$ for uranium miners. The dose per unit cumulative exposure has also been derived for environmental conditions (Harley and Pasternack 1981); the finding is in close agreement for the adult male $(0.71 \mathrm{rad} / W L M)$, adult female $(0.64$ $\mathrm{rad} / \mathrm{WLM}$ ), the 10-yr-old child (1.2 rad/ WLM) and the 1-yr-old infant $(0.64 \mathrm{rad} / \mathrm{WLM})$. The small differences in the dose for the miners and the doses received in environmental exposures reflect primarily the reduced breathing rates during normal environmental exposures, differences in lung morphometry, differences in particle size, and the increased percentage of unattached RaA in ordinary atmospheres ( $27 \%$ environmenta] vs $\sim 4 \%$ in mines). These conversion factors indicate that a cumulative exposure in the nonmining environment is scmewhat more effective in delivering a radiation dose to the lungs than are exposures under working conditions in a mine. In some models of risk from radon daughter exposure, there has been a tendency to artificially lower the cumulative exposure in the environment, presumably to account for decreased breathing rates under nonworking conditions and other factors (e.g., EPA 1980). In our opinion, this is neither warranted nor justifiable in view of the uncertainties associated with the various $\mathrm{rad} / \mathrm{WLM}$ values and the compensating factors mentioned above. Therefore, 
whether the exposure is environmental or occupational, the $\mathrm{WL}$ is given comparable weighting in our treatment of risk.

\section{RADON DAUGHTER EPIDEMIOLOGY STUDIES}

\section{Introduction}

The epidemiologic data derived from many types of underground mining show a relatively consistent relationship between lung cancer incidence (and mortality) and exposure to radon daughters. This underlying consistency is probably related to the relatively narrow range of bronchial dose per WLM under varying exposure conditions.

The assessment of the risk of attributable lung cancer through human epidemiologic studies is difficult because the detailed information required is not aiways available. In the ideal case, the exposure of each miner, as a function of time, would be available; the follow-up period would be sufficient for all of the group to have died of lung cancer or other causes. In addition, it would be possibie, from the data, to separate attributable lung cancers from those arising spontaneously or from cigarette smoking. The cumulative exposure, person-years at risk, and the number of attributable lung cancers would allow the exact calculation of a risk factor.

In reality, the data do not fulfill these requirements since estimates of exposure were often crude or worse, and follow-up periods are not sufficiently long. Nevertheless, recognizing the limitations of the data, it is possible to estimate a mean risk factor, which we can accept until improved data and studies provide more firmly based estimates of risk.

Human data are now available from several groups of underground metal ore miners: those in the U.S., Canadian and Czechoslovakian uranium mines; Swedish and British iron mines; Swedish lead and zinc 
mines; and Newfoundland fluorspar mines. Although other potential carcinogens (such as diesel smoke, traces of arsenic or nickel, and iron ore) are found in these mines, the lung cancer response based upon radon daughter exposure appears to be predictable. Some studies have divided the workers into subgroups on the basis of exposure. Eighteen subgroups were selected (Archer, Radford and Axelson 1979) as most suitable (considering both epidemiologic and environmental data) for quantitative treatment of the lower exposure levels. In addition to this treatment, these mining populations have been reviewed by other authors and organizations (see AxeTson and Sundell 1978; DeVilliers and Windish 1964; Evans et al. 1981; Jorgensen 1973; McCullough, Stocker and Makepeace 1979; NAS 1972, 1980; NCRP 1984; NIOSH/NIEHS 1971; Radford 1981; Renard 1974; Sevc, Kunz and Placek 1976; Snihs 1973, 1974; UNSCEAR 1977; Wright and Couves 1977).

Discussion and Summary

Present data suggest that an absolute threshold exposure for lung cancer induction is highly unlikely (this is also in keeping with the present-day views, in radiation biology and radiation protection, that radiation-induced cancer is a stochastic or nonthreshoid process). Evans (1967) and Stranden (1980) argue that the lung cancer mortality data at the lowest reported exposures are not statistically different from expected and that at least a "practical" threshold for radon daughter carcinogenesis may exist. Archer, Radford and Axelson (1979) conclude from their analysis of the 18 subgroups that, if a threshold exists, it is less than the range from 20 to $30 \mathrm{WLM}$. Snihs $(1973,1974)$ considers that the lowest underground exposure resuiting in an apparent increase in lung cancer deaths in Swedish miners is about 15 WLM, al though he states that it is impossible to draw conclusions about the exposure-response relationship below 100 WLM. Hewitt (1979) concludes from an analysis of Canadian uranium miners that, if a threshold exists, it is below 60 WLM. These varied opinions seem to indicate the 
possibility that environmental exposure to radon daughters (or very low-level exposures) does not result in lung cancer.

The incidence of lung cancer attributable to radon daughter exposure observed in the various mining subgroups ranges from about 1.5 to $50 \mathrm{cases} / \mathrm{WLM} /$ year $/ 10^{6}$ persons with a reasonable average value of $10 \mathrm{x}$ $10^{-6} /$ person-year/WLM. This average value has been accepted in the lung cancer prediction model of Harley and Pasternack (1981) as reasonably realistic when their modeled data are compared to background (nomaliy occurring) lung cancer incidence in nonsmokers from environmental exposure to radon.

In estimating the effect of radon daughter exposure at environmental levels (normally less than about 20 cumulative WLM per lifetime), the attributable risk at high exposures, derived from the mining data, must somehow be extrapolated to the iow-exposure region. In keeping with conventional practice, the extrapolation is linear, even though some studies suggest that exposures may be even more efficient in inducing lung cancer as the exposure rate approaches background levels (Archer, 1978).

\section{Influence of Cigarette Smoke}

The effect of cigarette smoke in modifying radiation-induced cancer probabilities remains unresolved at this time. During periods of relatively short follow-up (15 to 25 years), cigarette smoking is associated with a markedly increased incidence of lung cancer in miners. During 30- to 60-yr periods of follow-up after initial exposure, lung cancer incidence is reported to be either somewhat greater among nonsmokers than smokers (Axelson and Edling 1980) or about the same (Radford 1981b). This evidence is in agreement with the results of studies of beagle dogs that had comparable radon daughter exposures (Cross et al. 1978), where dogs that smoked had fewer respiratory tract tumors than dogs that did not smoke. The current evidence suggests that the principal role of cigarette smoking in uranium miners is to 
accelerate the appearance of lung cancer induced by radiation. However, the issue cannot be considered resolved as yet, and the role of smoking at low occupational or environmental radon daughter levels is unknown.

\section{ANIMAL STUDIES}

Introduction

Animal studies have been conducted for several decades to identify the nature and levels of uranium mine air contaminants that were responsibie for producing the lung cancers observed among uranium mining populations. Many of the initial studies were concerned with early effects or short-term pathologic changes (Jansen and Schuitzer 1926, Read and Mottram 1939, Jackson 1940). Exposures were based primarily on radon gas concentrations, giving little or no information on the radon daughter concentrations, which subsequentiy have been shown to contribute the greatest radiation dose to the lung. The early studies (Huech 1939; Rajewsky, Schraub and Schraub 1942a, 1942b; Kushneva 1959), in which lung tumors were produced, were methodologically or statisticaliy inadequate to show an unequivocal association of lung tumors with exposure to radon and/or radon daughters.

Beginning in the 1950s, a growing concern emerged that the increased incidence of respiratory cancer observed in the European uranium mining population would aiso be found in the U.S. mining population Seven State Uranium Mining Conference on Health Hazards, 1955; Wagoner et al. 1964). Systematic studies were subsequently begun in this country to identify the agents responsible for increased incidence of lung cancer in miners and to develop exposure-response relationships in animals. The importance of accurately determining the levels of radon daughter radionuclides in mine air was also pointed out by several investigators (Bale and Shapiro 1956, Harley 1953). Investigators at the University of Rochester began to focus attention on the biological and physical behavior of radon daughters as well as their contribution to the radiation dose to the respiratory tract (Bale and Shapiro 1951, Harris 1954, Morken 1955). Shapiro (1954) exposed rats and dogs to 
severa? levels of radon alone and in the presence of radon daughters attached to "room dust" aerosols. He also showed that the degree of attachment of radon daughters to carrier dust particles was a primary factor in influencing the a-radiation dose to the airway epitheifum and demonstrated that this dose was due primarily $(>95 \%)$ to the short-lived radon daughters $\mathrm{RaA}\left({ }^{218} \mathrm{Po}\right)$ and $\mathrm{RaC}^{\prime}\left({ }^{214} \mathrm{Po}\right)$, rather than to the parent radon.

In 1953 Cohn and coworkers reported relative levels of radioactivity found in the nasal passages, in the trachea and major bronchi, and in the other portions of rat lungs after exposure to radon and/or radon daughter products. The respiratory tracts of animals that inhaled radon plus its decay products contained 125 times more activity than those of animals that inhaled radon alone.

Beginning in the mid-1950s, Morken initiated a pioneering series of experiments (Morken and Scott 1966; Morken 1973a, 1973b) to evaluate the biological effects of inhaled radon and radon daughters in mice; later experiments used rats as well as beagle dogs. The essentially negative biological results of these studies suggested that a-irradiation is inefficient in producing tumors in the respiratory system. The only apparent permanent late changes occurred in the alveolar and respiratory bronchiolar regions of the lung for a wide range of exposure levels and for observation periods up to three years in the dog and one and two years, respectively, in the rat and mouse. Injury in the bronchial tissue was quickly repaired after irradiation ceased.

In the late 1960 s and early 1970s, studies, which later proved successful in producing lung tumors from inhaled radon daughters were initiated in France and the United States. At an average estimated lung dose of about 3000 rad from radon daughters, following prior lung stressing with stable cerium, $73 \%$ of the rats in the French studies developed malignant tumors (Perraud et a1. 1970). Subsequent French studies with rats exposed either to radon daughters alone or in combination with uranium ore dust and cigarette smoke were also successfu? in producing tumors in the lung (Chameaud et a1. 1974, 1980). The U.S. 
studies were designed to systematically determine the pathogenic role of radon daughters, alone or in various combinations with uranium ore dust, diesel engine exhaust fumes and cigarette smoke. These studies involved life-span exposures of beagle dogs and Syrian Golden hamsters (Cross et a). 1978). The later U.S. studies were also successful in producing tumors in the respiratory tracts of the animals (Cross 1985). Follow-up studies are currently being conducted in rats.

\section{Discussion and Summary}

The animal studies have provided considerable data confirming the human epidemiologic studies:

1. In rats primarily, tumor production per WLM at very high exposures was lower than at moderate exposures (Cross et a1. 1982, Chaumeaud et a . 1980). The lowest attributable lung cancer rates per unit exposure were observed in U.S. uranium miners and in Canadian fluorspar miners exposed to the highest radon daughter levels in underground mines.

2. In both the human and animal studies, tumor production appeared to increase with decrease in exposure rate (Cross et a1. 1982, 1984), al though exposure rate is considered to be less important than cumulative exposure.

3. In a small group of Swedish zinc/lead miners, a lower lifetime incidence of lung cancer was observed in those who smoked and were exposed to radon daughters than in those who were nonsmokers. This is tentatively ascribed to the protective effect of increased mucus production from smoking (Axelson and Sundell 1978) or of the thickened mucosa resulting from smoker's bronchitis. A similar result was observed in dogs (Cross et al. 1978). Tobacco smoke was found to be cocarcinogenic with radon daughters in rats when exposure to the smoke followed completion of exposure to the daughters (Chameaud et a1. 1980). This effect was not observed, however, when smoking preceded the radon daughter exposure 
(Chameaud et al. 1981). Such disparities may partialty explain discrepancies in interpreting epidemiologic data.

4. Emphysema has been attributed to radon daughter exposure in both animals--hansters, rats and dogs (Cross et al, 1978, 1982)--and underground miners. Simultaneous exposure to ore dust or diesel fumes did not appear to increase the number of tumors produced by exposure to radon daughters (Cross et al. 1978, 1982; Chameaud et a]. 1981).

5. For equivalent cumulative exposures, the older the anima? at the start of exposure, the shorter the latent period (Chameaud et al. 1981). In humans, the highest risk coefficient calcuiated, about $50 \times 10^{-6}$ lung cancers $/ \mathrm{yr} / \mathrm{WLM}$, is that for persons first exposed when over 40 years of age.

6. The predictions of the various dosimetric models appear to be borne out in the various species. The tumors induced in experiments with hamsters and rats, which have similar lung morphometry, occur primarily in the distal portion of the conducting airways or in the pulmonary region. The highest calculated dose (Desrosiers, Kennedy and Little 1978) was also predicted for these regions. Human tumors have appeared almost exclusively in the upper generations of the bronchial tree. Absorbed dose calculations show that basal cells in the upper airways, at about the level of the segmental bronchi, receive the highest dose from radon daughters (e.g., Harley and Pasternack 1972).

7. Lifetime risk coefficients are similar in both animals and humans. The coefficients based on rat data uncorrected for competing causes of death appear to range between 1 and $4 \times 10^{-4} / W L M$ for $a 11$ tumors (benign and malignant) at cumulative exposures less than 5000 WLM (Chameaud et al. 1981, Cross et al. 1985). At exposures considerably lower than levels at which life span is significantly shortened ( 2500 WLM), the lifetime risk coefficient appears to be about $2 \times 10^{-4} /$ WLM for malignancies, and ranges between 2 and $4 \times 10^{-4}$ 
for a11 tumors. Data are, as yet, insufficient to determine a value for exposures below $100 \mathrm{WLM}$, although the risk apparently does not decrease at exposures down to 20 LLM (Chameaud, Masse and Lafuma 1983).

\section{LUNG CANCER RISK PREDICTION MODEL}

The predictive model of Harley and Pasternack (Harley and Pasternack 1981, NCRP 1980) has been adopted for risk assessment in the APRA program because it allows risk coefficients to be developed for various age groups and exposure periods. This model is also used by the NCRP in their report on radon and radon daughter population exposures in the United States (NCRP 1984). It is based upon the most recent estimates of lung cancer deaths among underground uranium miners and accounts for the apparent increase in lifetime risk with increasing age at first exposure, as noted in epidemiologic studies of underground uranium miners. Although the model appears to represent reasonably the uranium miner lung cancer response, the validity of extrapolation to environmental levels is unknown. We assume that the model can be extrapolated to environmental levels on the basis of animal data and because of the present radiobiological concept that cancer induction is a nonthreshold process.

The adopted average yearly risk coefficient obtained for all exposure categories and ail age groups $\left(10 \times 10^{-6}\right.$ lung cancers/yr/WLM) corresponds to a lifetime risk (to age 85 years) of about 1 to $2 x$ $10^{-4}$ /WLM, dependent, of course, on activity, age at first exposure and duration of exposure. For comparison, ICRP (1981) has adopted a range for lifetime risk of 1.5 to $4.5 \times 10^{-4} / \mathrm{WLM}$, based primarily on Czechoslovakian underground mining data. Evans et al. (1981) estimated the lifetime risk (which, they state, is applicable to the general population) to be no greater than $10^{-4} / \mathrm{WLM}$ from U.S. and Czechoslovakian uranium miner epidemiologic data. Twice this value $\left(2 \times 10^{-4} /\right.$ WLM $)$ was adopted by Jacobi (1977) as the lifetime risk applicable to all types of miners; it is used by Cliff, Davies and Riessland (1979) to model lung cancer incidence from environmental exposure. 
UNSCEAR (1977) has reviewed the data on uranium miners in Canada, the United States and Czechoslovakia, on Swedish nonuranium miners and in iron miners in the United Kingdom. UMSCEAR states that the probabie lifetime lung cancer risk is 2 to $4.5 \times 10^{-4} /$ WLM. The Committee on the Biological Effects of Ionizing Fadiation (BEIR-III) reviewed lung cancer in U.S., Canadian and Czechoslovakian uranium miners, Newfoundland fluorspar miners and Swedish metal miners (NAS 1980). The range of risk for all groups (with emphasis on the lower exposure categories) was expressed as 6 to $47 \times 10^{-6}$ lung cancers/yr/WLM (rather than lifetime risk), the upper value being for those who began mining at age 40 or older. If we assume that lung cancer expression takes place over a 30-year interval (to account for the BEIR Committee's exclusion of the latent period in developing the yearly rate of risk), the 6 to $47 \mathrm{x}$ $10^{-6} /$ person/yr/WLM is equivalent to a range of 1 ifetime risk of about 2 to $14 \times 10^{-4} /$ WL.M.

The lifetime risk estimates for lung cancer attributabie to radon daughter exposure (per WLM) are therefore reasonably consistent, considering the difficulty in estimating this quantity without complete follow-up and the various methodological problems encountered in epidemiologic studies.

Other features of this predictive model are that lung cancer risk is expressed uniformily with time after exposure (with the restriction that tumors do not occur either before a five-year latent interval or before age 40), risk is corrected from year of exposure by an exponential factor (20-year half-time), which accounts for cellular repair, and an appropriate life table value is utilized to account for competing risks of death.

Although the basic incidence data from the underground mining epidemiologic studies cannot be applied directiy to environmental situations (because patterns of exposure differ), a common factor exists in the risk per rad for bronchial dose. The lifetime lung cancer risk attributable to an absorbed dose of $1 \mathrm{rad} / \mathrm{yr}$ has been calculated, using the conversion factor of $0.5 \mathrm{rad} / \mathrm{WLM}$ estimated for miners. For 
environmental exposure starting at one year of age, the lifetime risk (for exposure to age 85 years) is calculated to be $1.3 \times 10^{-2}$. Because exposure of a population involves persons of various ages, it is also necessary to know the lifetime risk of lung cancer induced by radon daughters for a population with age characteristics typical of the United States. This value, using the 1975 age distribution-for the United States (WHO 1978), is calculated to be $8.0 \times 10^{-3} / \mathrm{rad} / \mathrm{yr}$ exposure. These risk coefficients are suitable for calculating lung cancer risk from any source of radon daughter exposure.

Risk from a bronchial dose in rad per year to basal cells is not the most useful way to evaluate environmental exposures. Two more useful, lifetime risk coefficients can be derived that relate risk to environmental exposure in WLM per year and an annual exposure to a radon concentration of $1 \mathrm{pCi}^{222} \mathrm{Rn} / \mathrm{m}^{3}$.

As previousiy indicated, the average environmental exposure-to-dose conversion factors for the adult male, female, 10-yr-old child, and infant are $0.71,0.64,1.2$, and $0.64 \mathrm{rad} / \mathrm{wLM}$, respectively. The differences (from the $0.5 \mathrm{rad} / \mathrm{WLM}$ for miners) reflect reduced breathing rates under normal environmental exposures, differing lung morphometry, differences in particle sizes, and the increased percentage of unattached RaA in the environment. Extrapolation of mine data to environmental exposures is simplified considerably and contains very little error if we accept the environmental exposure-to-dose conversion factor of $0.7 \mathrm{rad} / \mathrm{WLM}$ (which applies to adult males) for all people. The lifetime risk estimate, which includes the effect of the higher dose conversion factor in childhood, is within 10\% of this value (see Tables 2 and 3 in Harley and Pasternack 1981). This conversion to WLM units places at $9.1 \times 10^{-3}$ the lifetime risk coefficient for beginning exposure at infancy; for populations with age characteristics of the United States in 1975 , it is $5.6 \times 10^{-3} / \mathrm{WLM} / \mathrm{yr}$ for 1 ifetime risk and Tifetime environmental exposure.

For the case of exposure measured as radon concentration over time, the average annual bronchial dose to an adult male from the daughters 
associated with exposure to $1 \mathrm{pCi}{ }^{222} \mathrm{Rn} / \mathrm{m}^{3}$ (assuming he is active 16 $\mathrm{h} /$ day and rests $8 \mathrm{~h} /$ day) is $2.7 \times 10^{-4} \mathrm{rad} / \mathrm{yr}$. Thus, the 1 ifetime risk for annual exposures to $1 \mathrm{pCi} / \mathrm{m}^{3}$ is calculated to be $3.6 \times 10^{-6}$ for exposure beginning at infancy, and (under the same exposure conditions) $2.1 \times 10^{-6}$ for populations of mixed age.

The above environmental iffetime risk coefficients are based on an unattached $R a A / R n$ ratio of 0.07 and an equilibrium factor of about 0.7 . The risk coefficjents can be adjusted for other unattachment fractions and radon daughter disequilibrium conditions. The more important adjustment for environmental exposures is considered to be the radon daughter equilibrium factor. Under some conditions of exposure the equilibrium factor is very low; the use of the radon gas risk coefficients would then produce an unnecessary conservatism in the estimated lung cancer predictions. On the other hand, the use of the above radon daughter risk coefficients when equilibrium factors are low result in underestimation of the 1 ung cancer risk. Table 3.1 provides data for adjusting the risk coefficients for other radon daughter disequilibrium conditions.

Table 3.1 Risk Coefficient Adjustment Factors vs Radon Daughter Disequilibrium

\begin{tabular}{|c|c|c|c|}
\hline $\begin{array}{c}\text { Radon and } \\
\text { Daughter Ratios }\end{array}$ & $\begin{array}{l}\text { Equilibrium } \\
\text { Factor } \\
\end{array}$ & 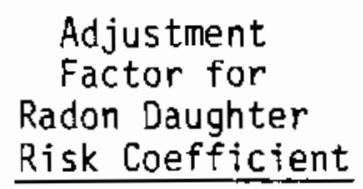 & $\begin{array}{r}\text { Adjustment } \\
\text { Factor for } \\
\text { Radon Gas } \\
\text { Risk Coefficient } \\
\end{array}$ \\
\hline $1 / 0.9 / 0.7 / 0.7$ & 0.71 & 1.00 & 1.00 \\
\hline $1 / 0.9 / 0.6 / 0.4$ & 0.55 & 1.05 & 0.81 \\
\hline $1 / 0.6 / 0.3 / 0.2$ & 0.29 & 1.30 & 0.53 \\
\hline $1 / 0.256 / 0.098 / 0.084$ & 0.11 & 2.21 & 0.34 \\
\hline
\end{tabular}




\section{Lifetime Risk from Environmental Exposure}

Lifetime lung cancer risk to populations from continuous environmental radon daughter exposure may be calculated, using any of the four coefficients described above, depending on the units of exposure. For example, a lifetime exposure to the average outdoor ${ }^{222} \mathrm{Rn}$ concentration of $200 \mathrm{pCi} / \mathrm{m}^{3}$ (Steinhausier et al. 1980, George and Breslin 1980) is $7 \times 10^{-4}$, i.e., 0.07\%. For comparison, Evans et a1. (1981) calculate a value one-third lower for equivalent concentrations. Indoor concentrations of radon are almost always higher than those outdoors because vertical mixing cannot take place indoors. Furthermore, in some cases, indoor radon levels may be increased by elevated ${ }^{226} \mathrm{Ra}$ concentrations in building materials and radon in the fuel and water supplies. The references cited above indicate that the average value for indoor radon concentration ranges between 600 and $800 \mathrm{pCi} / \mathrm{m}^{3}$, excluding basement concentrations. Using these data, typical average environmental exposure for single family dwellings approximates 500 $\mathrm{pCi} / \mathrm{m}^{3}$ (accounting for both indoor and outdoor exposures), which would result in a lifetime lung cancer risk of $2 \times 10^{-3}$. Since about half of the U.S. population resides in multistory buildings (Harley and Pasternack 1981), and indoor levels relate primarily to proximity to ground beneath the structure, the true average environmental exposure might be expected to 1 ie between these two values (i.e., about $0.13 \%$ ).

Haenszel et a7. (1958) proposed annual lung cancer rates (nonsmoking-related) of 33-39 and $57 \times 10^{-6}$ for women and men, respectively. For lifetime risk (ages 40-85), multiply these values by 45 , for an overall average value of $2 \times 10^{-3}, 0.2 \%$. There is evidence (Seidman, Silverberg and Holleb 1976) that in 1930, before cigarette smoking began to cause a major increase in lung cancer death5, the annual rates were about $16 \times 10^{-6}$ and $29 \times 10^{-6}$ for females and males, respectively. Incorporating these values would lower the average lifetime background incidence to about $10^{-3}$. Enstrom and Godley (1980) and Garfinkel (1980) have also reported the annual age-adjusted background lung cancer rates in the United States for nonsmokers. From their data, the Iifetime risks of 7 ung cancer for men and women are $10^{-2}$ and $5 \times 10^{-3}$, and $6 \times$ 
$10^{-3}$ and $4 \times 10^{-3}$, respectively, for the two studies. An average rounded value is $6 \times 10^{-3}$.

It is not possible to confirm the accuracy of the lung cancer prediction model for environmental background exposures to radon daughters. The model does project, however, that approximately $20 \%$ to $100 \%$ of the background (nonsmoking) lung cancer incidence can be attributed to environmental radon daughter exposure. The value is probably closer to $20 \%$, because of the uncertainty in the earlier data on nonsmoker lung cancer rates.

Calculation of Risks for the APRA Program

Radon and radon daughter concentrations, measured for residential and commercial buildings, are multipitied by the appropriate lifetime risk coefficient(s) for determination of the attributable risk of lung cancer from radon and radon daughter exposures. For example, the lifetime risk coefficient of $2.1 \times 10^{-6} / \mathrm{pCi} / \mathrm{m}^{3}$ radon concentration (considered appropriate for continuous exposure of populations of mixed ages and for persons of occupational age) would be used with the mean radon concentration and the number of persons exposed to provide an estimate of the total number of 1 ung cancers produced. For residential exposure, the risk coefficient applying to populations of mixed ages is considered more appropriate than that applying to infants. This choice is justifiable, in our view, considering the high mobility of the residents of the United States. Bogue (1959) has stated that, during the course of a single year, $20 \%$ to $22 \%$ of the inhabitants of the United States move from one house or apartment to another. Not more than $2 \%$ of the adult population will spend an entire lifetime in the same dwelling, and less than $15 \%$ will spend a lifetime in the same county. The tendency to relocate often is least frequent among children and the elderly, and most frequent among those between 17 and 32 years of age. Mobile homes and apartment units have high rates of turnover, whereas middle- and upper-class conventional-type homes have the lowest. The average occupancy time is probably about five years for all ages of residents and all types of homes. Graphically expressed, distribution of residency time versus frequency would probably appear lognormal. 
The significance of population mobility is that the additional individual lung cancer risk for residents in homes with high radon concentration is small if the residence time is short. The effect of population mobility tendencies is to distribute the cancer risk among a greater number of persons, those who may at some time reside in one of the dwellings with increased levels of indoor radon.

Finally, an 80\% time occupancy factor is assumed for persons exposed to indoor radon concentration in homes and a $23 \%$ time (i.e., $2000 \mathrm{~h} / \mathrm{yr}$ ) occupancy factor for persons employed in conmercial buildings. Adjustments in these occupancy times can be made for special circumstances. The attributable risk from radon (radon daughter) exposures can be compared with the present lifetime risk of lung cancer (about 4\% in the United States, according to Evans et al. 1981), which is largely attributable to cigarette smoking.

Accuracy of Risk Prediction from Model

Myers and Stewart (1979) have shown an underiying Tung cancer incidence in uranium mines that is not dependent on radon daughter exposure and may represent the effect of other carcinogens. Of course, a similar factor (exposure to environmental cocarcinogens) may confound the interpretation of population exposures. Thus, the risk factors may be similar for all radon (radon daughter) exposures.

The predictive model proposed for use in the APRA program utilizes a lifetime risk coefficient between 1 and $2 \times 10^{-4} / \mathrm{WLM}$ and concludes that a significant portion of the nonsmoking lung cancer incidence may be due to background radon exposures. The predictive mode?, therefore, is not unreasonable from the standpoint of overestimating the background incidence. The vaiues derived from this model are thought, however, to represent upper-boundary incidences; true values may be lower, but how much lower is uncertain. The model should be useful, however, for predicting changes in risk with changes in exposure (e.g., from remedial actions) if the following remain relatively constant: particle sizes of the carrier aerosols for the radon daughters, the degree of disequi- 
librium, and the degree of unattachment of radon daughters. We conclude that the absolute values of risk are known to within a factor of two, but we believe that the change in risk for a change in exposure is quite accurately modeled.

\section{REFERENCES}

Altshuter, B., N. Nelson and M. Kuschner. 1964. "Estimation of lung tissue dose from the inhalation of radon and daughters," Health Phys. $10: 1137$.

Archer, V. E. 1978. "Summary of Data on Uranium Miners." In Workshop on Dosimetry for Radon and Radon Daughters, Oak Ridge National Laboratory, April 12-13, 1977, p. 23, ORNL-5348, National Technical Information Service, Springfield, Virginia.

Archer, V. E., E. P. Radford and O. Axelson. 1979. "Radon daughter cancer in man: Factors in exposure response relationship." In: Conference Workshop on Lung Cancer Epidemiology and Industrial Applications of Sputum Cytology, p. 324. Colorado School of Mines Press, Golden, CO.

Axelson, 0. and L. Sunde11. 1978. "Mining, lung cancer and smoking." Scand. J. Work Environ. Health $4: 46$.

Axelson, 0. and C. Edling. 1980. "Heal th hazards from radon daughters in Sweden." In: HeaTth Implications of New Energy Technologies, W. N. Rom and V. E. Archer, eds, p. 79. Ann Arbor Science Pubtishers Inc., Ann Arbor, Michigan.

Bale, W. F. 1951. "Hazards Associated with Radon and Thoron." Memo dated March 14, 1951, Division of Biology and Medicine, Atomic Energy Commission, Washington, DC. 
Bale, W. F. and J. S. Shapiro. 1956. "Radiation dosage to lungs from radon and its daughter products." In: Proceedings, U.N. International 1975 Conference on Peaceful Uses of Atomic Energy, Vor. 13, p. 233. United Nations Publications, New York.

Bogue, D. J. 1959. The Population of the United States p. 375. Glencoe, Illinois, Free Press of Glencoe.

Chameaud, J., R. Perraud, J. Lafuma, R. Masse and J. Pradel. 1974. "Lesions and Lung Cancers Induced in Rats by Inhaled Radon-222 at Various Equilibriums with Radon Daughters." In: Experimental Lung Cancer. Carcinogenesis and Bioassays, p. 411. E. Karbe and J. F. Park, eds. Springer-Verlag, New York.

Chameaud, J., R. Perraud, J. Chretien, R. Masse and J. Lafuma. 1980. "Combined Effects of Inhalation of Radon Daughter Products and Tobacco Smoke." In: Pulmonary Toxicology of Respirable Particles, p. 551. C. L. Sanders, F. T. Cross, G. E. Dagle and J. A. Mahaffey, eds. CONF-791002, National Technical Information Service, Springfield, Virginia.

Chameaud, J., R. Perraud, R. Masse and J. Lafuma. 1981. "Contribution of Animal Experimentation to the Interpretation of Human Epidemiological Data." In: Proceedings of International Conference Radiation Hazards in Mining: Control, Measurement and Medical Aspects, p. 222. M. Gomez, ed. Kingsport Press Inc., Kingsport, Tennessee.

Chameaud, J., R. Masse and J. Lafuma. 1983. "Influence of Radon Daughter Exposure at Low Doses on Occurrence of Lung Cancer in Rats." Radiat. Prot. Dosim., 7:385.

Cliff, K. D., B. L. Davies and J. A. Reissland. 1979. "Little Danger from Radon." Nature 279:12. 
Cohn, S. H., R. K. Skow and J. K. Gong. 1953. "Radon inhalation studies in rats." Arch. Ind. Hyg. Occup. Med. 7:508.

Cross, F. T., R. F. Palmer, R. E. Filipy, R. H. Busch and B. 0. Stuart. 1978. Study of the Combined Effects of Smoking and Inhalation of uranium Ore Dust, Radon Daughters and Diesel $0 i 1$ Exhaust Fumes in Hamsters and Dogs, Pacific Northwest Laboratory Final Report PNL-2744/UC-48. Nationa1 Technical Information Service, Springfield, Virginia.

Cross, F. T., R. F. Palmer, R. H. Busch and R. L. Buschbom. 1982. "Influence of Radon Daughter Exposure Rate and Uranium Ore Dust Concentration on Occurrence of Lung Tumors." In: Proceedings of Specialist Meeting on Assessment of Radon and Daughter Exposure and Related Biological Effects, p. 189. G. F. Clemente et al, eds. R.o. Press, Salt Lake City, Utah.

Cross, F. T., R. F. Palmer, R. H. Busch, G. E. Dagle, R. E. Filipy and H. A. Ragan. 1985. "An Overview of the PNL Radon Experiments with Reference to Epidemiological 0ata." In: Proceedings, 22nd Annual Hanford Life Sciences Symposium, September 27-29, 1983, Richland, Washington.

Cross, F. T., R. F. Paimer, G. E. Dagle, R. H. Busch and R. L. Buschbom. 1984. "Influence of Radon Daughter Exposure Rate, Unattachment Fraction, and Disequilibrium on Occurrence of Lung Tumors." Radiat. Prot. Dosim. 7:38:.

Desrosiers, A. E., A. Kennedy and J. B. Little. 1978. " ${ }^{222}$ Rn daughter dosimetry in the Syrian Golden hamster 1ung." Health Phys. 35:607.

Oevilliers, A. J. and J. P. Windish. 1964. "Lung cancer in a fluorspar mining community: I. Radiation dust and mortality experience, "Br. J. Ind. Med. 21:94. 
Enstrom, J. E. and F. H. Godley. 1980. "Cancer mortality among a representative sample of non-smokers in the United States during 1966-68." J. Natl. Cancer Inst. 65:1175.

EPA Division of Criteria and Standards. 1980. Draft Environmental Impact Statement (DEIS) for Remedial Action Standards for Inactive Uranium Processing Sites, Environmental Protection Agency Report EPA 52014-80-011. U.S. Environmental Protection Agency, Washington, D.C.

Evans, R. D. 1967. "On the Carcinogenicity of Inhaled Radon Decay Products in Man (CORD)." Report submitted before the Joint Committee on Atomic Energy, Subcommittee on Research, Development and Radiation, July 1967: Hearings on Radiation Exposure of Uranium Miners, Part 2, p. 1188. U.S. Government Printing Office, Washington, DC.

Evans, R. D., J. H. Harley, W. Jacobi, A. S. McLean, W. A. Mills and C. G. Stewart. 1981. "Estimate of Risk from Environmental Exposure to Radon-222 and its Decay Products," Nature 290:98.

Fry, R. M. 1977. "Radon and its Hazards." In: Proceedings of HEA Specialist Meeting, Personal Dosimetry and Area Monitoring Suitable for Radon and Daughter Products, p. 13. Nuclear Energy Agency, OECD, Paris.

FRC. 1967. Guidance for the Control of Radiation Hazards in Uranium Mining. Federal Radiation Council Staff Report No. 8 (revised). U. S. Government Printing Office, Washington, DC.

Garfinke1, L. 1980. "Cancer mortality in non-smokers: Prospective study by the American Cancer Society," J. Natl. Cancer Inst. 65:1169.

George, A. C. and A. J. Breslin. 1980. "The distribution of ambient radon and radon daughters in residential buildings in the New Jersey-New York area." In: The Natural Radiation Environment III, Houston, Texas. Technical Information Center/U.S. Department of Energy. 
Haensze1, W., M. B. Shimkin and N. Mante1. 1958. "A Retrospective Study of Lung Cancer in Women." J. Nat1. Cancer Inst. 21:825.

Haque, A. K. M. M. 1966. "Energy Expended by alpha particies in lung tissue," Br. J. Appt. Phys. 17:905.

Haque. A. K. M. M. 1967. "Energy Expended by alpha particles in lung tissue. III. A computer method of calculation." Br. J. Appl. Phys. $18: 657$.

Haque, A. K. M. M. and A. J. L. Collinson. 1967. "Radiation dose to the respiratory system due to radon and its daughter products." Health Phys. 13:431.

Harley, J. H. 1953. "Sampling and measurement of air-borne daughter products of radon." Nucleonics 11:12.

Harley, N. H. and 8. S. Pasternack. 1972. "Alpha absorption measurements applied to lung dose from radon daughters." Health Phys. 23:771.

Harley, N. H. and B. S. Pasternack. 1981. "A model for predicting lung cancer risks induced by environmental levels of radon daughters." Health Phys. 40:307.

Harris, S. J. 1954. "Radon exposures in various mines." Paper presented to the Ind. Health Conf., Chicago, IL, Aprit 28, 1954.

Hewitt, D. 1979. "Biostatistical studies on Canadian uranium miners." In: Conference/Workshop on Lung Cancer Epidemiology and Industrial Applications of Sputum Cytology, Pp. 264 and 398. Colorado School of Mines Press, Golden, Colorado.

Hofmann, W. 1982. "Cellular Lung Dosimetry for Inhaled Radon Decay Products as a Base for Radiation-Induced Lung Cancer Risk Assessment II. Microdosimetric Calculations." Radiat. Environ. Biophys 20:113. 
Huech, W. 1939. "Kurzer Bericht uber Ergebnisse Anatomischer Utersuchungen in Schneeburg." Z. Krebsforschung 49:312.

ICPP 1977. Radiation Protection in Uranium and Other Mines, ICRP Publication 24, International Commission on Radiological Protection. Pergamon Press, New York.

ICRP 1981. Limits for Inhalation of Radon Daughters by Workers, ICRP Publication 32, International Commission on Radiological Protection. Pergamon Press, New York.

Jackson, M. L. 1940. The Biological Effects of Inhaled Radon. Master's Thesis, Massachusetts Institute of Technology, Cambridge, MA.

Jacobi, W. 1964. "The dose to the human respiratory tract by inhalation of short-lived $222 \mathrm{Rn}$ and $220 \mathrm{Rn}$-decay products." Health Phys. 10:1163.

Jacobi, W. 1972. "Relations between the inhaled potential a-energy in the bronchial and pulmonary region." Health Phys. 23:3.

Jacobi, W. 1977. "Interpretation of Measurements in uranium mines: dose evaluation and biomedical aspects." In: Proceedings of NEA Specialist Meeting, Personal Dosimetry and Area Monitoring Suitable for Radon and Daughter Products, p. 33. Nuclear Energy Agency, OECD, Paris. Jacobi, W. and K. Eisfeld. 198D. Dose to Tissues and Effective Dose Equivalent by Inhalation of Radon-222, Radon-220 and their Short-Lived Daughters. Geselischaft fur Strahlen-und Umweltforschung MBH, Report GSF S-626 (Institut fur Strahlenschutz, Munich-Neuherberg, Germany).

James, A. C., J. R. Greenhalgh and A. Bircha1l. 1980. "A Dosimetric Model for Tissues of the Human Respiratory Tract at Risk from Inhaled Radon and Thoron Daughters." In: Radiation Protection. A Systematic Approach to Safety, p. 1045. Proc. 5th Congress IRPA, Jerusalem, March 1980, Vol. 2, Pergamon Press, Oxford. 
James, A. C., H. Jacobi and F. Steinhausler. 1981. "Respiratory Tract Dosimetry of Radon and Thoron Daughters: The State-of-the-Art and Implications for Epidemiology and Radiobiology." In: Proceedings of International Conference Radiation Hazards in Mining: Control, Measurement, and Medical Aspects, M. Gomez, ed., p. 42. Kingsport Press Inc., Kingsport, Tennessee.

Jansen, H. and P. Schultzer. 1926. "Experimentà investigations into the internal radium emanation therapy. I. Emanatorium experiments with rats." Acta Radiol. 6:631.

JCAE 1967. Joint Committee on Atomic Energy, Subcommittee on Research Development and Radiation, Congress of the United States, Ninetieth Congress, May-August 1967: Hearings on Radiation Exposure of Uranium Miners (U.S. Government Printing Office, Washington).

JCAE 1969. Joint Committee on Atomic Energy, Subcommittee on Research Development and Radiation, Congress of the United States, Ninety-first Congress, March 17 and 18, 1969: Hearings on Radiation Exposure of Uranium Miners (U.S. Government Printing Office, Washington).

Jorgensen, H. S. 1973. "A study of mortality from lung cancer among miners in Kiruna, 1950-1970." Work Environ. Health 10:126.

Kushneva, V. S. 1959. "On the Problem of the Long-Term Effects of Cornbined Injury to Animals of Silicon Dioxide and Radon," AEC-TR4473, p. 22.

McCultough, R., H. Stocker and C. E. Makepeace. 1979. "Pilot study on radon daughter exposures in Canada." In: Conference/Workshop on Lung Cancer Epidemiology and Industrial Application of Sputum Cytology, p. 183. Colorado School of Mines Press, Golden, Colorado.

McPherson, R. B. 1979. Environmental Radon and Radon Daughter Dosimetry in the Respiratory Tract, PNL-2898. Pacific Northwest Laboratory Report. National Technical Information Service, Springfield, Virginia. 
Morken, D. A. 1955. "Acute toxicity of radon." AMA Arch, Ind. Health $12: 435$.

Morken, D. A. 1973a. "The biological effects of the radioactive noble gases." In Noble Gases, R. E. Stanley and A. A. Moghissi, eds., p. 469. National Environmental Research Center Report CONF-730915. National Environmental Research Center, Las Vegas, Nevada.

Morken, D. A. 1973b. "The biological effects of radon on the lung." In: NobTe Gases, R. E. Staniey and A. A. Moghissi, eds., p. 501. National Environmental Research Center Report CONF-730915. National Environmental Research Center, Las Vegas, Nevada.

Morken, D. A. and J. K. Scott. 1966. Effects on Mice of Continual Exposure to Radon and Its Decay Products on Dust. University of Rochester Atomic Energy Project, Report UR-669. National Technical Information Service, Springfield, Virginia.

Myers, D. K. and C. G. Stewart. 1979. "Some Health Aspects of Canadian Uranium Mining." In: Conference/workshop on Lung Cancer Epidemiology and Industrial Applications of Sputum Cytology, p. 368. Colorado School of Mines Press, Golden, Colorado. Also in Chalk River Laboratory Report AECL5970.

NAS 1972. The Effects on Populations of Exposure to Low Levels of Ionizing Radiation (BEIR Report). National Academy of Sciences. U.S. Government Printing Office, Washington.

NAS 1980. The Effects on Populations of Exposure to Low Levels of Ionizing Radiation (BEIR-III Report). National Academy of Sciences. National Academy Press, National Academy of Sciences, Washington, DC 20418. 
NCRP 1980. "NCRP Response to Federal Register of $6 / 27 / 80$ Request for Public Comment on Radon in Inhabited Structures." July 17, 1980 letter with enclosure to W. H. Ellett, Office of Radiation Programs, U.S. Environmental Protection Agency, Washington, DC 20460.

NCRP 1984. Evaluation of Occupational and Environmental Exposures to Radon and Radon Daughters in the United States, National Council on Radiation Protection and Measurements, Report No. 78, Bethesda, MD.

NeTson, I. C. et a1. 1974. A Further Appraisal of Dosimetry Related to Uranium Mining Health Hazards, U.S. Pubiic Heal th Service Report CPE 69-1131. National Institute of Occupational Safety and Health, Cincinnati, Ohio.

NIOSH/NIEHS 1971. Radon Daughter Exposure and Respiratory Cancer Quantitative and Temporal Aspects. National Institute for Occupational Safety and Health/National Institute of Environmental Health Sciences, Joint Monograph No. 1. National Technical Information Service, Springfield, VA.

Parker, H. M. 1969. "The dilemma of lung dosimetry." Health Phys. $16: 558$.

Perraud, R., J. Chameaud, R. Masse and J. Lafuma. 1970. "Cancer Pulmonaries Experimentaux Chez le Rat apres inhalation de Radon associe a des Poussieres non Radioactives." Compt. Rend. Ser. D. 270:2594.

Radford, E. P. 1981a. "Lung Cancer Risk from Radon Daughters, and the Problem of Appropriate Standards of Exposure in Underground Mines." In: Proceedings of International Conference Radiation Hazards in Mining Control, Measurement and Medical Aspects, M. Gomez, ed., Kingsport Press Inc., Kingsport, Tennessee.

Radford, E. P. 1981b. "Radon Daughters in the Induction of Lung Cancer in Underground Miners." Banbury Report 9, Quantification of Occupa- 
tional Cancer, R. Peto and M. Schneiderman, eds., p. 151. Cold Spring Harbor Laboratory, N.Y.

Rajewsky, B., A. Schraub and E. Schraub. 1942a. "Uber die toxische Dosis by Einatmung von Ra-Emanation." Naturwissenschaften 30:489.

Rajewsky, B., A. Schraub and E. Schraub. 1942b. "Zur Frage der Toleranz-Dosis bei der Einatmung von Ra-Em." Naturwissenschaften $30: 733$.

Read, J. and J. C. Mottram. 1939. "The 'tolerance concentration' of radon in the atmosphere." Br. J. Radiol. 12:54.

Renard, K. G. 1974. "Respiratory cancer mortality in an iron mine in northern Sweden." Ambia 3:67.

Seidman, H., E. Silverberg and A. I. Holleb. 1976. "Cancer Statistics, 1976. A Comparison of white and BTack Populations." Ca-A Cancer Journal for Clinicians, 26:18-19.

Sevc, J., E. Kunz and V. P1acek. 1976. "Lung cancer in uranium miners and long term exposure to radon daughter products." Health Phys. $30: 433$.

Seven State Uranium Mining Conference on Health Hazards. 1955. Hote] Utah, Salt Lake City, Utah.

Shapiro, 3. 1954. An Evaluation of the Pulmonary Radiation Dosage from Radon and its Daughter Products. University of Rochester Atomic Energy Project Report UR-298. University of Rochester, Rochester, New York.

Snihs, J. 0. 1973. "The significance of radon and its progeny as natural radiation sources in Sweden." In: Noble Gases, R. E. Stanley and A. A. Moghissi, eds., p. 115. National Environmental Research Center Report CONF-730915. National Environmental Research Center, Las Vegas, Nevada. 
Sniths, J. 0. 1974. "The approach to radon problems in non-uranium mines in Sweden." In: Proceedings of the Third International Congress of the International Radiation Protection Association, p. 900. U.S. Atomic Energy Commission Report COMF-730907. National Technical Information Service, Springfield, Virginia.

Steinhausler, F., W. Hofmann, E. Pohl and J, Pohl-Ruling. 1980. "Local and temporal distribution pattern of radon and daughters in an urban environment and determination of organ dose frequency distributions with demoscopical method." The Natural Radiation Environment III, Houston, Texas, Apri1 1978. Technical Information Center, U.S. Department of Energy.

Stranden, E. 1980. "Radon in dwellings and lung cancer. A. discussion." Health Phys. 38:301.

UNSCEAR 1972. Ionizing Radiation: Levels and Effects. United Nations Scientific Conmittee on the Effects of Atomic Radiation. United Nations, New York.

UNSCEAR 1977. Sources and Effects of Ionizing Radiation. United Nations Scientific Committee on the Effects of Atomic Radiation. United Nations, New York.

USPHS 1957. Control of Radon and Daughters in Uranium Mines and Calculations on Biologic Effects, Pub. 494. United States Public Health Service. U.S. Government Printing office, Washington.

USPHS 1961. Governor's Conference on HeaTth Hazards in Uranium Mines, A summary report, USPHS Publication No. 843. U.S. Public Health Service, Bureau of State Services, Washington, D.C..

Wagoner, J. K., V. E. Archer, B. E. Carrol and D. A. Holaday. 1964. "Cancer Mortality Patterns Among U.S. Uranium Miners and Millers, 1950 through 1962." J. NatT. Cancer Inst. 32:787. 
Walsh, P. J. 1970. "Radiation dose to the respiratory tract of uranium miners." Environ. Res. 3:14.

Waish, P. J. 1971. "Relationship of experimental to empirical findings and theoretical dose calculations." Final Report of Subgroup IB, Inieragency Uranium Mining Radiation Review Group. EPA, Rockvil7e, Maryland.

Walsh, P. J. 1979. "Dose conversion factors for radon daughters." Health Phys. 36:601.

WHO 1978. World Health Statistics Annual. Worid Health Organization, Geneva.

Wise, K. N. 1982. "Dose Conversion Factors for Radon Daughters in Underground and Open-Cut Mine Atmospheres." Health Phys. 43:53.

Wright, E. S. and C. M. Couves. 1977. "Radiation-induced carcinoma of the lung - the St. Lawrence tragedy." J. Thorac. Cardiovasc. Surg. $74: 495$. 
CHAPTER 4

INGESTION DOSE MODELS

In addition to direct exposure from gamma rays and inhalation of radon and its daughters, ingestion of radionuclides may occur through either agricultural use of the land or home gardening. Of initial importance in this study is consideration of the internal organ doses of individuals conducting home gardening activities on land contaminated with uranium tailings. Integrated organ doses are calculated for the conditions at individual residential sites, using the PABLIA computer program (Napier, Kennedy, and Soldat 1980). An integrated dose period of 50 years is selected for consistency with the direct gamma and radon daughter inhalation health effects estimates.

The PABLM (Napier, Kennedy, and Soldat 1980) computer program was written to facilitate the calculations of integrated internal organ doses for individuals or population groups during periods of continuous chronic exposure. The radiation dose models in the PABLM computer program consider several exposure pathways. These include exposure to radionuclides deposited on the ground or food crops from contaminated air or irrigation water, exposure to residual contamination in soil or food crops grown in contaminated soil, ingestion of contaminated drinking water, and ingestion of food products raised in contaminated water. The equations for calculating internal radiation doses are derived from those given by the International Commission on Radiological Protection (ICRP) for body burdens of each radionuclide considered. A total of 19 incestion pathways for various food products may be selected with corresponding consumption rates, growing periods, and air or water concentrations or deposition rates. The concentrations of radionuclides in contaminated soil are corrected to account for radioactive decay during the chronic exposure period. The PABLM computer program can be used to calculate integrated doses to 23 possible 
body organs or tissues for any one radionuclide or combination of radionuclides. A maximum of five organs and a mixture of up to 100 radionuclides may be selected for any single computer run.

Internal doses are calculated as a function of the radionuclide concentration in food products, ingestion rates, and radionuclide-specific dose factors. The ingestion rate of food products is assumied to be constant over the chronic exposure period (set here at 50 years). Dose factors for each organ are calculated using the methods of ICRP Publication 2 (1959).

The fundamental equation for calculation of integrated radiation dose from radionuclides in environmental pathways is as follows (Napier, Kennedy and Soldat 1980, Appendix A):

$$
D_{i p r}=\sum_{T=1}^{\text {No. of } Y_{r}} c_{i p}(T) U_{p} F_{i p r}(T)
$$

where:

$$
\begin{aligned}
& D_{i p r}=\text { the dose commitment to organ } r \text { from radionuclide } i \text { via } \\
& \text { pathway } p \text { in rem, } \\
& C_{i p}(T)=\text { the concentration of radionuclide } i \text { in the medium of } \\
& U_{p}=\text { the usage, i.e. exposure or intake rate associated with } \\
& \text { pathway } \mathrm{p} \text { in } \mathrm{kg} / \mathrm{yr}, \ell / \mathrm{yr} \text {, or } \mathrm{h} / \mathrm{yr} \text {, } \\
& F_{i p r}(T)=\text { a specific dose factor for radionuclide } i \text {, pathway } p \text {, }
\end{aligned}
$$


The concentrations of radionuclides in food products are calculated as intermediate steps in PABLM for each year of continuous exposure. For vegetation, the concentration of radionuclides at the time of harvest from root uptake is:

$$
c_{i r}=c_{i s} B_{i v} / P
$$

where:

$$
\begin{aligned}
C_{i r}= & \text { the vegetation concentration from root uptake in } p C i / \mathrm{kg}, \\
B_{i v}= & \text { the concentration ratio for } p \text { lant uptake of radionuclide } \\
& i \text { in } p C i / \mathrm{kg} \text { (wet weight) per } p C i / \mathrm{kg} \text { (dry weight) soil, } \\
P= & \text { the soil "surface density" in } \mathrm{kg} \text { (dry soil)// taken to be } \\
& 224 \mathrm{~kg} / \mathrm{m}^{2} \text { (Soldat and Harr, 1971). }
\end{aligned}
$$

The usage parameter in Equation $4.1,\left(U_{p}\right)$, depends on the exposure pathway considered. For this study, five food product pathways are assumed. These food products are intended to represent the types of foods that could be grown in a backyard garden. They include leafy vegetables, other above-ground vegetables, potatoes, other root vegetables, and orchard fruit. Estimates of the potential growing period, crop yields, and consumption (or usage), shown for the total annual diet of the average individual for these food products, are given in Table 4.1 .

The form of the dose commitment factor, $F_{i p r}(T)$ from Equation 4.1 , depends upon the exposure pathway considered. For ingestion pathways, radionuclides may accumulate in the body so that one year of ingestion may result in a dose received over a several-year period. The PABLM computer program uses ICRP Publication 2 (1959) mode1s and effective decay energies. This model is based on the assumption that the entire quantity of a given 
TABLE 4.1 Food Product Data

\begin{tabular}{lccc} 
Food Type & $\begin{array}{c}\text { Growing } \\
\text { Period (days) }\end{array}$ & $\begin{array}{c}\text { Yield } \\
\left(\mathrm{kg} / \mathrm{m}^{3}\right)\end{array}$ & $\begin{array}{c}\text { Consumption } \\
(\mathrm{kg} / \mathrm{yr})\end{array}$ \\
\cline { 1 - 1 } $\begin{array}{l}\text { Leafy vegetables } \\
\begin{array}{l}\text { Other above- } \\
\text { ground vegetables }\end{array}\end{array}$ & 60 & 1.5 & 15 \\
$\begin{array}{l}\text { Potatoes } \\
\text { Other root } \\
\text { vegetables }\end{array}$ & 90 & 0.7 & 15 \\
Orchard fruit & 90 & 4.0 & 80 \\
& 90 & 5.0 & 30
\end{tabular}


radionuclide is located at the center of a spherical organ with an appropriate effective radius (Soldat et al. 1974). Metabolic parameters from ICRP Publication 23 (1975) for standard man are used in the calculations. The committed radiation dose equivalent per picocurie per year ingested, $F_{i p r}$ for organ $r$, for a period $T_{i}$ following ingestion is as follows (Napier, Kennedy and Soidat 1980):

$F_{i p r}\left(T_{2}\right)=0.0187 \frac{f_{w i r} E_{i r}}{m_{r}\left(\lambda^{2}\right)}\left[T_{1 \lambda e}+e^{-\lambda e^{T} 2}-e^{-\lambda_{e}\left(T_{2}-T_{1}\right)}\right]$

where:

$F_{i p r}\left(T_{2}\right)=$ the dose commitment for $T_{2}$ years following ingestion of a radionuclide at the rate of one picocurie/yr over $T_{1}$ years in rem/pCi over $\mathrm{T}_{2}$ years,

$0.0187=$ a unit conversion factor $=$

$$
\left(1.602 \times 10^{-8} \frac{\mathrm{g} \mathrm{rad}}{\mathrm{MeV}}\right)\left(\frac{0.037 \mathrm{dis}}{\mathrm{sec} \mathrm{pCi}}\right)\left(\frac{3.15 \times 10^{7} \mathrm{sec}}{\mathrm{yr}}\right)
$$

$f_{\text {wir }}=$ the fraction of radionuclide $i$ ingested reaching organ $r$

$E_{i r}=$ the effective decay energy of radionuclide $i$ in organ $r$, in MeV per disintegration,

$m_{r}=$ the effective mass of organ $r$ in grams, 
$T_{1}=$ the intake time, taken to be I yr in PABLM,

$T_{2}=$ the time over which the dose is integrated, taken to be 50 years,

$\lambda_{e}=$ the effective removal half-time, related to the biological half-time, $T_{B i}$, and the radiological half-time, $T_{R i}$, as

$$
\lambda_{e}=\frac{0.693\left(T_{R i}+T_{B i}\right)}{T_{R i} \cdot T_{B i}} y r^{-1}
$$

Using Equation 4.3, the total accumulated dose over $T_{2}$ years to an organ of reference, $r$, from ingestion of food products is as follows (Napier, Kennedy and Soldat 1980):

$D_{r}=\sum_{T=1}^{T_{2}} \sum_{p=1}^{\begin{array}{c}\text { No. of food } \\ \text { pathways }\end{array} \sum_{i=1}^{\text {No. of }} \text { radionuclides }} c_{i p}(T) U_{p} F_{i p r}\left(T_{2}-T\right)$

The results of an example calculation using the PABLM computer program for uranium tailings are shown in Table 4.2. This table contains 50-year integrated doses to the organs of an individual who ingests his entire fruit and vegetable diet (Table 4.1) from a backyard garden. The organs for which doses are calculated are: total body, kidneys, liver, bone, and lower large intestine (GI-LLI). The soil concentration assumed for this example calculation is $100 \mathrm{pCi}$ of ${ }^{226} \mathrm{Ra}$ and daughters per gram of soil, plus $10 \mathrm{pCi}$ per gram of $234 \mathrm{~J}, 238 \mathrm{U}$, and their daughters per gram of $50 \mathrm{it}$. To obtain integrated doses for a site containing a similar radionuclide mixture, the dose values shown must be corrected for the actual soil concentration $(\mathrm{pCi} / \mathrm{g})$ and the fraction of the total diet grown on-site. For example, if the soil concentration were $200 \mathrm{pCi} / \mathrm{g}$, and only $10 \%$ of the fruit and vegetabie segment of the diet were grown at a site, the 50-year integrated total-body dose would be about $52 \mathrm{rem}$, and the bone dose would be about $240 \mathrm{rem}$. Health-effects risk factors of 100 cancers $/ 10^{6}$ man-rem for total body, and 
10 cancers $/ 10^{6}$ man-rem for bone are assumed for internal doses for the models used in this study.

TABLE 4.2. Fifty-Year Integrated Doses to an Individual Ingesting Fruits and Vegetables Grown in a Uranium Tailings/Soil Mixture ${ }^{(a)}$

\section{Integrated Organ Doses (rem)}

\begin{tabular}{|c|c|c|c|c|c|}
\hline Radionuclide & Total-Body & Kidneys & Liver & Bone & GI-LLI \\
\hline${ }^{234} \mathrm{U}$ & $1.5 \times 10^{-2}$ & $5.5 \times 10^{-2}$ & $--(b)$ & $2.3 \times 10^{-1}$ & $1.9 \times 10^{-2}$ \\
\hline${ }^{23 D^{T h}}$ & $1.4 \times 10^{-1}$ & $1.5 \times 10^{0}$ & $2.8 \times 10^{-1}$ & $4.7 \times 10^{1}$ & $3.2 \times 10^{-1}$ \\
\hline $226_{\mathrm{Ra}}$ & $2.2 \times 10^{2}$ & -- & $\cdots$ & $2.8 \times 10^{2}$ & $5.9 \times 10^{-1}$ \\
\hline $210_{\mathrm{Pb}}$ & $3.8 \times 10^{1}$ & $8.7 \times 10^{2}$ & $2.8 \times 10^{2}$ & $9.5 \times 10^{2}$ & $4.7 \times 10^{0}$ \\
\hline${ }^{210} \mathrm{Bi}$ & $1.8 \times 10^{-2}$ & $2.6 \times 10^{0}$ & $2.1 \times 10^{-1}$ & $3.2 \times 10^{-2}$ & $3.7 \times 10^{0}$ \\
\hline $2: 0_{0}$ & $8.3 \times 10^{-1}$ & $2.4 \times 10^{1}$ & $7.1 \times 10^{0}$ & $3.5 \times 10^{0}$ & $7.1 \times 10^{-1}$ \\
\hline${ }^{238} \mathrm{U}$ & $1.3 \times 10^{-2}$ & $4.7 \times 10^{-2}$ & -- & $2.1 \times 10^{-1}$ & $1.7 \times 10^{-\hat{\imath}}$ \\
\hline${ }^{234} \mathrm{Th}$ & $9.1 \times 10^{-7}$ & $9.9 \times 10^{-6}$ & $1.7 \times 10^{-6}$ & $3.1 \times 10^{-5}$ & $4.7 \times 10^{-2}$ \\
\hline TOTALS & $2.6 \times 10^{2}$ & $9.1 \times 10^{2}$ & $2.9 \times 10^{2}$ & $1.2 \times 10^{3}$ & $9.9 \times 10^{0}$ \\
\hline
\end{tabular}

(a) Based on dose factors using ICRP 2 (1959) models at a soil concentration of $100 \mathrm{pCi} / \mathrm{g}$.

(b) A dash (--)indicates a transfer factor $\left(f_{\text {wir }}\right)$ of zero. 
Thus, the resulting cancer risks from ingestion for an individual in the example case are 0.0052 for tota 1 body and 0.0024 for bone.

To correct the calculations for natural uranium and daughters in soil, the average crustal abundance of $238 \mathrm{U}$ in soils is determined to be $0.6 \mathrm{pCi} / \mathrm{g}$ (NCRP 1975). Since ${ }^{226}$ Ra is at equilibrium with the uranium, it is also present with an average concentration of $0.6 \mathrm{pCi} / \mathrm{g}$. This concentration is far less than the ${ }^{226} \mathrm{Ra}$ concentration associated with uranium mill tailings and is used as a correction factor in the dose calculations where sitespecific background data are lacking.

\section{REFERENCES}

ICRP 1959. Report of ICRP Committee II on Permissible Dose for Internal

Radiation. International Conmission on Radiological Protection Publication 2. Pergamon Press, New York, New York.

ICRP 1975. Report of the Task Group on Reference Man. International Commission on Radiological Protection Publication 23. Pergamon Press, New York, New York.

Napier, B. A., W. E. Kennedy, Jr. and J. K. Soldat. 1980. PABLM - A Computer Program to Calculate Accumulated Radiation Doses from Radionuclides in the Environment PML-3209. Pacific Northwest Laboratory, Richland, Washington.

NCRP 1975. Natural Background Radiation in the United States. Nationa Council on Radiation Protection and Measurements Report No. 45, Bethesda, MD.

Soldat, J. K. and R. D. Harr. 1971. "Radiation Dose Mode1." In: MERMES--' A Digital Computer Code for Estimating Regional Radiological Effects from the Nuclear Power Industry, HEDL-TME-71-68, pp. 81-175. J. F. Fletcher and W. L. Dotson, compilers. Hanford Engineering Development Laboratory, Richland, Washington. 
Soldat, J. K. et al. 1974. Models and Computer Codes for Evaluating Environmental Padiation Doses. BNWL-1754. Pacific Northwest Laboratory, Richland, Washington. 
1

 
CHAPTER 5

\section{A REVIEW OF RADIOLOGICAL RISK ASSESSMENT METHODOLOGIES FOR URANIUM MILL TAILINGS PILES ANO VICINITY PROPERTIES}

INTRODUCTION

Assessments of the radiological hazards associated with uranium tailings piles have been performed by various engineering firms, research laboratories, and national as well as international organizations. These assessments generally address five pathways by which man is exposed to radioactivity from the tailings piles: (1) radon diffusion from the pile; (2) airborne particulate radioactivity due to wind; (3) radioactivity ingested through the intake of food grown on land contaminated by airborne tailings ; (4) radioactivity that enters the body through aquatic pathways; and (5) exposure to direct gamma radiation. Of these five pathways, the major potential health risk to the public comes from the inhalation of radon progeny derived from tajingsradon "trapped" for a period of time in structures downind from the piles and, secondarily, from external gamma radiation. In general, pathways 2,3 , and 4 can be neglected (EPA, 1982) because it appears that their contribution to potential health effects is less than the error associated with the estimates of the radon concentrations. While our interest iles primarily in the risk assessment methodologies for intentionaliy displaced tailings material, such as that used for landfill, there is a common ground of interest in the risk coefficients used for calculating health effects, regardless of whether the exposures are derived from the piles themselves or from tailings transported to vicinity structures or properties. Examples of health effects calculations for displaced tailings are not as plentiful as those pertaining to the tailings piles themselves. The former appear to be 7 imited to calculations by ORNL and PNL. The following reviews pertinent details of the assessment methodologies described in their documents by DOE remedial action contractors other than PNL. The PNL risk assessment methods were discussed in Chapter 2. 
RADIOLOGICAL ASSESSMENT METHODOLOGY OF ORNL

The radiological assessment methodology of ORIL for tailings pile radionuclides and for formerly utilized MED/AEC sites with uranium-chain radionuclides are detailed in the following two documents:

ORNL 1977. Assessment of Radiological Impact of the Inactive Uranium-Mill Tailings Pile at Salt Lake City, Utah, Oak Ridge National Laboratory, Oak Ridge, Tennessee, November, 1977, ORNL/TM-5251.

Cotter, S. J., J. P. Witherspoon and G. S. Hi11. 1981. Ranking of Formerly Utilized MED/AEC Sites According to Radiation Dose, Oak Ridge National Laboratory report prepared for the U.S. DOE, Oak Ridge National Laboratory, Oak Ridge, Tennessee, December, 1981.

The items of interest in ORNL 1977 are the radon daughter and gamma risk coefficients. Potential health effects from continuous exposure to radon progeny and external whole-body gamma radiation were estimated using data provided in the 1972 BEIR report (NAS 1972). It was assumed that lung cancer accounted for $26 \%$ of the total (absolute) cancer risk for $a 11$ age groups. The ir derived lung cancer death risk was 18 deaths/yr in a population of $10^{6}$ persons exposed to $1 \mathrm{rem} / \mathrm{yr}$ postpartum. Further, assuming that an exposure to radon progeny of $1 \mathrm{WLM} / \mathrm{yr}$ produced a carcinogenic lung dose of $10 \mathrm{rem} / \mathrm{yr}$ to members of the general public, continuous exposure to $1 \mathrm{WLM} / \mathrm{yr}$ ultimately produced 180 deaths $/ y r / 10^{6}$ persons, which is equivalent to a lifetime lung cancer risk of $1.8 \times 10^{-4} / \mathrm{WL}$ M exposure. Indoor radon daughter equilibrium was assumed to average $50 \%$.

In assessing whole-body exposures to gamma radiation, it was assumed that 1 roentgen ( $R$ ) in air is equivalent to 1 rem in tissue (a reasonable assumption). The absolute risk coefficient for cancer, including leukemia, was taken from the BEIR report to be about 100 deaths/yr for a continuous radiation dose equivalent rate of 1 rem/yr to a population of $10^{6}$ persons. This is equivalent to a lifetime total cancer risk of $10^{-4} / \mathrm{rem}$ whole-body gamma dose. 
The items of interest in the document by Cotter and colleagues are aiso the radon daughter and gamma risk coefficients; however, other exposure pathways are treated. Fifty-year dose commitments resulting from inhalation of resuspended radionuclides from contaminated soil, with some modification: for ${ }^{226} \mathrm{Ra}$ and from ingestion of vegetable crops contaminated by way of root uptake, were taken from Hill (1979). Exposure-to-dose conversion factors for radon daughters were assumed to average $1 \mathrm{mrem} / \mathrm{yr} / \mathrm{pCi} / \mathrm{m}^{3}$, a reasonable assumption for occupationa exposure. For unrestricted site use, individuais were assumed to live in a wooden frame house constructed on the property. Exposures to gamma radiation were apportioned at $130 \mathrm{hr} / \mathrm{yr}$ outdoors (1.5\%) and $6062 \mathrm{hr} / \mathrm{yr}$ indoors $(69.2 \%)$. The wooden structure afforded a shielding factor of 0.4 for gamma radiation from contaminated soi1; radioactivity was assumed to be uniformly distributed in the top $15 \mathrm{~cm}$ of soil. The ingestion exposure pathway assumed an individual living on the site produced and consumed $0.08 \mathrm{~kg}$ of vegetables per day in a home garden.

Total-body dose commitments were converted to lifetime cancer risk using the coefficient $10^{-4} /$ rem. This value and other organ-specific cancer and genetic risk coefficients (excluding lung) were taken from ICRP publication 26 (ICRP 1977). The risk factor for radiation-induced lung cancer, $7 x$ $10^{-6} /$ rem, was supposedly taken from BEIR-III. An upper annualized value of 7 $\times 10^{-6} / \mathrm{yr} / \mathrm{rem}$ dose is listed in BEIR-III, but no lifetime risk per rem dose to lung couid be found. The comparable ICRP-26 value for lifetime lungcancer risk is $2 \times 10^{-5} / \mathrm{rem}$. No attempt was made to exclude background concentrations from the radon-daughter risk calculations.

An update of the radiological assessment methodology and supporting data of ORNL for indoor radon exposures appears in the following two documents:

ORNL 1983a. Radon Dosimetry: A Review of Radon and Radon Daughter Exposure Conditions in Dwellings and 0ther Structures. ORNL/ TM-5286, Oak Ridge Nationa? Laboratory, Oak Ridge, Tennessee.

ORNL 1983b. Assessing the Risk from Exposure to Radon in Dwel1ings. ORNL/TM-8824, Oak Ridge National Laboratory, Oak Ridge, Tennessee. 
ORNL 1983a is valuable for its review of the avaliable data on normal radon and radon daughter concentrations in dwellings and other structures. This type of data is necessary for calculating the attributable risk rather than the tota? risk at a particular site. Pooled data from the United States and Canada showed a lognomal distribution for radon on the first floor of residential structures with a mean of $2.5 \mathrm{pCi} / \mathrm{L}$ and a geometric standard deviation (GSD) of 4.8. In basements, the mean value is $7.1 \mathrm{pCi} / \mathrm{L}$ with a GSD of 3.5. Corresponding vaiues for pooled data on radon daughters are $0.007 \mathrm{WL}$ with a GSD of 3.3 on the first floor of residential structures and $0.014 \mathrm{WL}$ with a GSD of 3.5 for basements. These radon and radon daughter concentrations are approximately double the values of the National Academy of Sciences (NAS 1980), reflecting a large component of data from unusually high background areas in Canada. The usual, approximate doubling of basement concentrations over first-floor concentrations, however, remains intact.

Pooled radon daughter data in structures and dwellings constructed on "reclaimed or altered land" in uranium or phosphate mining areas showed a mean first-fioor concentration of $0.011 \mathrm{WL}$, with a GSD of 2.8 .

Other factors that affect the dosimetry (and thus the risk assessment) of radon daughter exposures are the variation in radon gas concentrations and the degree of unattachment and disequilibrium of the radon daughters. Daily variations in radon concentration were from one-third to three times the average, with considerable room-to-room variations within a given structure. Weekly and seasonal variations ranged from one-haif to twice the average daily concentrations. It was considered appropriate to assume that true average radon concentrations 1 ie between one-third to three times a particular grab sample measurement.

The free ion or unattachment fraction of the first daughter of radon ranged from 0.05 to 0.07 at the $95 \%$ confidence interval. The degree of disequilibrium was related to the ventilation rate of the structure and was $0.7,0.5$, and 0.4 , respectively, at air exchange rates of $0.5,1.0$, and 1.5 $\mathrm{h}^{-1}$. This document clearly portrays the need for a sufficient number of measurements of radon and radon daughters to adequately define the true 
annual average and distribution of exposures within a structure. In sumary, the document (with some exceptions) provides a reasonable data base for subtracting background exposures for calculation of the risk attributable to radon from tailings.

ORNL 1983b reviews the dosimetry bases and methods of risk assessment for indoor radon daughter exposures. Assuming a background value of $0.007 \mathrm{WL}$ for first-floor radon daughter concentrations, a 70-yr exposure period, and assuming that $80 \%$ to $90 \%$ of a day is spent indoors, lifetime exposures were calculated to range from 20 to $23 \mathrm{WLM}$. Further, assuming a relative risk, based on uranium miner experience, to be $0.4 \%$ to $1 \% / W L M$, a lifetime exposure is calculated to represent an $8 \%$ to $23 \%$ increase in lung cancer $[(20$ to 23 WLM $)(0.4 \%$ to $1 \% / W(M)]$. These calculations are a departure from the conventional use of the absolute risk model generally employed in radon-daughter risk assessments.

Apart from the data and approaches enumerated above, a series of reports were also issued by ORNL detajling survey data and including health risk calculations for specific vicinity properties related to the vitro pile in Salt Lake City. Although mention was made of potential exposures of individuals via aquatic and food pathways, as well as from inhalation of resuspended particulate radioactivity, actual calculations of risk were confined to direct gamma-ray exposures and to the inhalation of radon and radon daughters. These calculations utilized lifetime (absolute) risk coefficients for total-body gamma and radon daughter exposures (generally for 50-yr, but sometimes for $70-y r$, exposure periods) of $10^{-4} / \mathrm{rem}$ and $10^{-4} / \mathrm{WLM}$, respectively. Approximate background values were subtracted from these exposures, thereby yielding risks attributable to the displaced tailings material contaminating the properties, or, for closely situated properties, to the radionuciides associated with the pile. These risk factors are reasonable choices for simple, preliminary estimates of risk to occupants of tailingscontaminated properties. They do not account for differences in the ages of the persons exposed, but rather pertain to populations of: mixed ages. Considering the paucity of exposure measurements at these vicinity properties, especialiy for radon daughters, it could be argued that a more sophisticated approach is unnecessary. Neglecting food-chain pathways, however, 
especiaily for Salt Lake City residents who grow a higher than average amount of their food supply, potentially underestimates the risk to residents of private properties. These risk calculations also do not attempt a more sophisticated approach to deriving mean annual exposures of occupants of the vicinity properties but rather use simple averages of (for the most part) grab-sample data.

In summary, we have examined a number of approaches by ORNL to risk estimation as well as a range of risk coefficients. To some extent this variety represents the fast changing data base and risk approaches by national and international scientific organizations. It undoubtediy also represents the varied opinions of the many different investigators who have modeled risk at ORNL.

RADIOLOGICAL ASSESSMENT METHODOLOGY OF FORD, BACON AND DAVIS UTAH, INC.

The radiological assessment methodology for tailings-pile radionuclides of Ford, Bacon and Davis Utah, Inc. appears in the following two documents:

FBDU 1978. Radiation Pathways and Potential Health Impacts from Inactive Uranium Mill Tailings, GJT-22, FBDU130-41. Ford, Bacon and Davis Utah, Inc., Sait Lake City, Utah.

FBDU 1981. Engineering Assessment of Inactive Uranium Mil]

Tailings, Vitro Site, Salt Lake City, Utah, DOE/UMT-0102, FBDU360-0D. Ford, Bacon and Davis Utah, Inc., Salt Lake City, Utah.

These documents assess the health impacts of the Vitro pile itself. The first document does not assess the external garma ray exposures, nor the inhalation of windblown tailings, but considers the health impact to populations of these pathways to be insignificant. A modeling of the ground-and surface-water pathway predicted a potential exposure of less than $10^{-4}$ mren/yr, a negligible dose compared with that from the radon daughters. Exposures from the ingestion of food were also ignored; like the external gamma and windblown tailings, this pathway was considered to be insignificant. In assessing the impact of radon daughter exposures, modeled indoor 
radon concentrations were converted to WL concentrations, assuming a $50 \%$ equilibrium factor (a generally conservative assumption, which, in some cases, could well overestimate the radon daughter risk) and continuous exposure (100\% of the time spent indoors). The radon daughter (absolute) risk estimator (1.8 $\left.\times 10^{-4} / \mathrm{WLM}\right)$ was derived from BEIR (NAS 1972); the relative risk estimates of BEIR were considered less useful.

The second document updates the data and assessments in the first document and other predecessor FBDU reports. It also ignores the radiological impact of all exposures other than those due to radon daughters and whole-body gamma radiation. The radon-daughter (absolute) risk estimator $\left(1.5 \times 10^{-4} / \mathrm{WLM}\right)$ is derived from underground miner data in BEIR-III (NAS 1980) by assuming a lifetime plateau for risk to age 75 , adjusting for the reduced breathing rates of populations compared with the rates of miners, and adjusting for the population age distribution. These adjustments could be criticized, but the derived risk factor is not unreasonable and is in the range of factors used by others. As in FBDU 1978, indoor radon daughter concentrations are derived from indoor radon concentrations, assuming an equilibrium factor of $50 \%$. The gamma risk estimator is confusing, being a combination of a linear and quadratic term and expressed in annualized units. Example calculations of gamma risk are not given.

RADIOLOGICAL ASSESSMENT METHODOLOGY OF SANDIA NATIONAL LABORATORIES

Sandia's radiological assessment methodology for tailings-pile radon appears in the following docliment:

Sandia 1981. Uranium Mil1 Tailings and Radon. SAND80-2.142 (Revision). Sandia National Laboratories, Aibuquerque, New Mexico.

Sandia, like severa? others, conservatively assumes $50 \%$ equilibrium for radon daughters in indoor air as well as continuous exposure; thus $1 \mathrm{pC} i / \mathrm{L}$ radon = $0.25 \mathrm{WLM} / \mathrm{yr}$. Their exposure-to-dose conversion factor is $5 \mathrm{rem} / \mathrm{WL} M$, a factor of about two less than that of most others. Sandia adopted the arnualized risk estimate of the 1976 ad hoc committee of BEIR (NAS 1976), 2 lung cancer 
cases $/ \mathrm{rem} / 10^{6}$ person-yr, which they convert to 10 lung cancer deaths/WLM/ $10^{6}$ person-yr. Rather than deveioping their own cancer-prediction model around this risk coefficient, Sandia adopted the methodology of EPA as it appears in the DEIS for remedial action standards for inactive uranium processing sites (EPA 1980). EPA's approach in their final environmental impact statement (40 CFR 192) (EPA 1982) for radon and gamma exposures is simitar and is as follows:

- $\quad$ Radon dispersion from tailings sites is conservatively modeled, not measured; indoor radon concentrations are set equal to outdoor levels; indoor radon daughter concentrations are calculated, assuming an equilibrium factor of $70 \%$.

- I WL for $1 \mathrm{yr}$ is equivalent to $27 \mathrm{WLM} / \mathrm{yr}$, rather than to $51 \mathrm{WLM} / \mathrm{yr}$. This exposure reduction presumabiy accounts for the different equilibrium factor and the reduced breathing rate of members of the population, compared to worker exposures. (a)

- The occupancy time for structures is 75\%; therefore, 1 WL for 1 yr equals 20 WLM.

- The annualized absolute risk coefficient is 10 lung cancer deaths/WLM/ $10^{6}$ person-yr at risk, a value reported by the NAS (1976). Assuming a constant risk following expasure, and accounting for other causes of death, a person exposed to $0.01 \mathrm{WL}$ over a 1 ifetime is stated to incur a $0.7 \%$ ( 1 in 140) additional chance of contracting a fatal lung cancer. Assuming $71 \mathrm{yr}$ of exposure and $0.01 \mathrm{WL}=0.20 \mathrm{WLM} / \mathrm{yr}$, the 1 ifetime (absolute) risk coefficient of EPA converts to $5 \times 10^{-4} / \mathrm{WLM}\left[\left(7 \times 10^{-3} ; \div\right.\right.$ $(0.20 \times 71)]$. This value is considerably higher than the lifetime risk coefficient used by other madelers; however, the artificial lowering of population exposures keeps the EPA risk estimates reasonably near

(a) A reduction for breathing rate is a mistaken notion, however, as the dose to bronchial tissue (the presumed site for cancer induction) is roughly invariant with respect to breathing rate. 
(although higher than) the values calculated by other health effects modelers.

- EPA also employs relative risk model, which predicts approximately twice as many lung cancer deaths as their absolute risk model.

- A gamma-ray exposure of $100 \mathrm{mrem} / \mathrm{yr}$ produces a lifetime (absolute) risk of fatal cancer of $8 \times 10^{-4}$. This equates to an absolute lifetime risk of about $10^{-4} / \mathrm{rem}$, a value commonly used for assessing the risk of gamma-ray exposures. The EPA's relative risk model provides a risk coefficient for fatal cancers from whole-body gamma-ray exposures six times greater than their absolute risk model.

SUMMARY

The majority of risk assessments associated with radionuclides from uranium mill tailings have been addressed to the piles themselves. Two laboratories, ORNL and PNL, addressed the risks associated with tailings-contaminated vicinity properties. The major risks are due to radon daughter and external gamma radiation exposures. Other pathways of exposure are mentioned but, except for the food pathway, are not considered important enough to include in risk calculations.

Lifetime absolute risk coefficients for radon daughter exposures range from 1 to $5 \times 10^{-4} / \mathrm{WLM}$ in the documents surveyed. Lifetime relative risk coefficients range even higher. Despite the wide range in absolute risk coefficients, the range of predicted lung cancers was narrower due to compensatory assumptions in the calculations. Although the agreement is fortuitous, many assumptions contributing to the agreement cannot be justified scientifically. The lifetime whole-body absolute risk coefficient for external gamma radiation exposure was commoniy chosen to be $10^{-4} / \mathrm{rem}$ whole-body dose.

The ORNL risk assessment methodology for vicinity properties is the simplest and is arguably adequate when the exposure data are very limited. 
The uncertainties in the risk estimates, however, could easily exceed a factor of five when calculated with inadequate exposure data.

PNL's approach, discussed in Chapter 2, is more sophisticated. The risk coefficients, which are based on a recent NCRP report (NCRP 1984), are adjusted to exposure conditions at individual properties. An-attempt is made to calculate realistic annual-equivalent exposures for occupants of vicinity properties. The types of risks and estimated health effects calculated by PNL also provide an improved basis for setting priorities for remedial action and for the determination of cost-benefit ratios.

ADDITIONAL REFERENCES

EPA 1980. "EPA Draft Environmental Impact Statement for Remedial Action Standards for Inactive Uranium Reprocessing Sites." Office of Radiation Programs, Environmentai Protection Agency, Washington, March 1980.

EPA 1982. "EPA Final Environmental Impact Statement for Remedial Action Standards for Inactive Uranium Reprocessing Sites (40 CFR 192)." Office of Radiation Programs, Environmental Protection Agency, Washington, June 1982.

Hi17, G. S. 1979. Doses for Various Pathways to Man Based on Unit Concentrations of Radionuclides Pertinent to Decontamination and Decommissioning of Properties, ORNL/OEPA-7. Oak Ridge National Laboratory, March 1979.

ICRP 1977. "Recommendations of the International Commission on Radiological Protection," ICRP Publication 26. Pergamon Press, New York, January 1977.

NAS 1972. "The Effects on Populations of Exposure to Low-Levels of Ionizing Radiation." National Academy of Sciences, National Research Council, Report. of the Advisory Committee on the Biological Effects of Ionizing Radiations (BEIR), Washington, November 1972. 
NAS 1976. "Health Effects of Alpha-Emitting Particles in the Respiratory Tract." NationaT Academy of Sciences, National Research Council, Report of the Ad Hoc Committee on "Hot Particies" of the Advisory Committee on the Biological Effects of Ionizing Padiations (BEIR), Washington, 0ctober 1976.

NAS 1980. "The Effects on Populations of Exposure to Low Levels of Ionizing Radiation," National Academy of Sciences, National Research Council, Report of the Committee on the Biological Effects of Ionizing Radiations (BEIR-III), Washington, July 1980.

NCRP, 1984. "Evaluation of 0ccupational and Environmental Exposure to Radon and Radon Daughters in the United States," NCRP Report No. 78. National Council on Radiation Protection and Measurements, Bethesda, MD. 
CHAPTER 6

REVIEW OF RADIDLOGICAL SURVEY TECHNIQUES USED IN DOE REMEDIAL ACTION PROGRAMS FROM THE STANDPOINT OF RISK ASSESSHENT

INTRODUCTION AND SCOPE

This chapter provides a review of the radiological survey protocols used with in the DOE Remedial Action Programs with respect to the type of data available for performing risk analyses. The review includes radiological survey protocols identified in generic DOE Remedial Action program documents, as well as those given in site-or property-specific survey reports. Some protocol documents outside DOE's Remedial Action programs were also reviewed for comparison and completeness.

This review includes the past and current radiological survey techniques employed for DOE's Remedial Action Programs and the protocols developed by the Technical Measurements Center (TMC) in Grand Junction, Colorado. The TMC provides standardization, calibration, testing of comparability, verification of data, quality assurance, and evaluation of cost-effectiveness for the environmental measurements required for DOE's Remedial Action Programs. A 1 ist of documents reviewed in developing this chapter is included in the Supplemental Bibliography. These include those for the Formerly Utilized Sites Remedial Action Program (FUSRAP), i.e., DOE/EV-0005-XX(1-50); the Uranium Mill Tailings Remediai Action Program (UMTRAP), e.g., ORNL-XXXXX(5447-5465); and the generic documents provided by TMC, e.g., GJ/TMC-XX(02-16), and by others, e.g., DOE/EP-01100, NUREG/CR-2082 and -2241 . The types of surveys included in these respective reports are summarized in tables, following the discussion of the types of surveys most useful for performing risk estimates. Examples are also provided, showing how the available data from the Salt Lake City vicinity property surveys were used to perform property-specific risk estimates. Finally, recommen- 
dations are provided for reviewing and reevaluating the need for and subsequent use of radiological surveys for comparison with standards and guidelines as well as performing risk estimates for occupants of the facilities or parcels of land.

\section{DOE REMEDIAL ACTION PROGRAM SURVEY PROTOCOLS}

The DOE Remedial Action Program's radiological characterization surveys of site and vicinity properties typically include gamma scan and exposure rate measurements at indoor and outdoor locations, and instantaneous indoor air sampling for radon or radon daughters. Other measurements at selected sites and for specific programs also include sampling of surface $(0$ to $15 \mathrm{~cm}$ ) and subsurface soil, and alpha and beta-gamma contamination measurements inside buitdings. The specific survey protocols for each of the DOE programs, grouped by program and potential contaminants, are described in more detail in the sections that follow.

\section{Bases for Radiological Surveys}

Each DOE Remedial Action Program uses different terminology to describe the radiological surveys they corduct. Generally the surveys can be categorized as: (1) initial, (2) characterization/engineering, and (3) verification. The initial surveys identify contaminated properties for possible incorporation into one of the DOE Remedial Action programs. The characterization/engineering surveys are really extensions of the initial surveys to further delineate the contaminated areas and to identify which portions of specific properties would require subsequent remedial actions. The verification surveys are performed subsequent to remedial action to verify that applicable guidelines have been met, and no further remedial action is required. We emphasize the characterization surveys because they include the most detail and, hence, are the most useful for performing risk analyses.

The types of measurements most often collected by the survey teams are those taken to show that a particular property is not contaminated above a given guideline. Hence, there is a strong emphasis on making 
so-called "biased" measurements to show that contaminant levels for a given property are below the standard. In fact, the latest trend in making radiological surveys at UMTRAP-vicinity properties is to perform "biased" surveys only; that is, to Jook only for "hot spots" and to compare those levels with the guidelines, rather than to make measurements at fixed intervals in space or time that would allow the calculation of concentration or radiation level averages and trends.

In general, the radionuclides of interest are determined from a history of the operations conducted at a given site or from the contaminants, such as tajings material, which were deliberately displaced for fill or construction or indirectly through wind or water erosion. For those sites affected by uranium mill tailings, the most important nuclides are ${ }^{238} \mathrm{U},{ }^{226} \mathrm{Ra}$, and the daughters of ${ }^{222} \mathrm{Rn}$. Hence, the most important measurements for risk estimation include external garma radiation (from the decay of ${ }^{226} \mathrm{Ra}$ and its daughter products), radon daughters in air, ${ }^{226} \mathrm{Ra}$ in soil (and, ultimately, in foodstuffs) and water (when relevant and availabie). For the FUSRAP, the same radionuclides and measurements may also be important, but additional radionuclides may include fission (e.g., ${ }^{90} \mathrm{Sr}$ and ${ }^{137} \mathrm{Cs}$ ) and activation

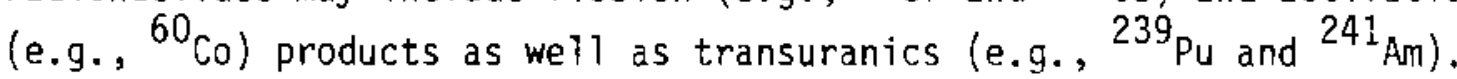
It is essential, however, that a thorough search of the site or facility records of operational history be included and some analyses performed to assure the absence of specific contaminants.

\section{GJRAP and UMTRAP Survey Methods}

The Grand Junction survey program was started in 1968. At that time, an indoor radon study of Mesa County (Colorado) was initiated by the U.S. Public Health Service (PHS) and the Colorado Department of Health $(\mathrm{CDH})$. Those initial screening surveys indicated the need for further study, which prompted a joint effort begun in April 1970 by the $A E C$, the EPA and Colorado State University (CSU). These early efforts attempted to characterize the radiological condition of residences and 
commercial structures with respect to the need for remedial action based on the then-applicable Surgeon General Guidelines (i.e., whether or not occupied or habitable structures showed radon daughter concentrations of greater than 0.01 , between 0.01 and 0.05 , or greater than $0.05 \mathrm{WL}$ ).

Presently, the radiological survey responsibilities for GJRAP are split between the CDH and an architect/engineering firm, ARIX Corporation (ARIX). The state is charged with making annual average radon daughter air-concentration measurements in occupied or habitable structures while ARIX performs the balance of the surveys as part of their radiological monitoring support (RMS) contract. ARIX technicians also obtain grab air samples during the construction phase as a preliminary indication of the remedial action effectiveness. ARIX also analyzes airborne radioactivity in the work area and provides for dust controls when needed. The objectives of the RMS program are "to document radiological conditions prior to, during and after construction, and to provide radiological assistance in aitering the original design if necessary" (ARIX 1983, p. 8-4). The general guidelines and specific details of the GuRAP radiological surveys are provided in Section 8 (Radiological Monitoring Support) and Appendices A (Dose Rate Calibration and Gamma Surveying), G (State of Colorado/ARIX Contract), $H$. (Contract for Engineering Assessment), K (Engineering Assessment Forms and Reports), and L (Priority Determination Procedures) of the Proccdures Manual for the Grand Junction Remedial Action Program (ARIX 1983).

The objectives of GJRAP gamma-screening surveys are to determine if radioactive materials, especially uranium mill tailings deposits, are present on individual properties; to acquire sufficient data to evaluate the gamma radiation levels; and to document the location of tailings or other radioactive material when detected. ARIX performs all gama surveys.

Hethods used to search for elevated gamma radiation fields and to characterize them are grouped into two types. The first is single-point measurements made at the intersection of grid lines that represent a 
sample of the gamma field surrounding the grid line intersections. This method is usually employed for screening surveys outside a structure where large areas are to be mapped. The second type is a scan of individual areas bordered by the grid lines. The average value is noted for the grid block. This second method has the advantage of locating less obvious sources that might be away from the grid line intersections and is used in smaller areas, such as inside structures.

For the typical outdoor survey, 6- to 10-foot grid intervals are used. When surveying inside, 5-foot scan intervals are used, including around and over furniture. These scan (slow-walk) readings are taken with the meter held just off the surface of the ground or floor where possible. Waist-level readings are also made to detect point sources on shelves and in storage areas and to help delineate an area of elevated readings by checking for "shine" fields. If higher waist-level readings are observed, the surveyor is directed to investigate the surrounding area in an attempt to locate the source of the "shine."

When anomalies are encountered, either indoors or outside, a differential gamma reading is also obtained, using a portable lead shield. In these cases, a reading is taken with the field survey instrument (gamna scintillator) in both a shielded and an unshielded mode at the same location (and height above the surface), and the differential reading is recorded (typically in $R / h r$ ).

Explorations, a combination of concrete/asphalt coring and soil flight augering, are performed in interior and exterior areas at locations of gamma anomalies. Core samples are obtained where tailings use is suspected, and holes augered and radiation levels logged until essentialiy background levels are detected at the bottom of the hole to assure that the bottom of the tailings deposit has been reached. Explorations are also required adjacent to and to depths below the footings of the structure(s) on the site to verify if tailings were used as backfil1. In addition, all exterior masonry is surveyed for anomalies, with readings being obtained and recorded on both the brick and the mortar surfaces. 
In the case of radon daughter measurements, the $\mathrm{CDH}$ performs these measurements at GJRAP vicinity properties. The radon daughter concentration (RDC) data, measured in terms of working levels, are accumulated over a one-year period in accordance with 10 CFR 712. The radon daughter samples are normally collected from one interior location representing the greatest possibility for elevated concentrations. These measurements, using radon-progeny-integrated sampling units (RPISU), consist of six nominally 100-hour samples per year separated by a minimum of four weeks at each property. The state RDC data are usualiy considered adequate to determine WL exposure rates unless remodeling and source material removal have been accomplished by the owner subsequent to the sampling effort. In such cases, simultaneous grab radon and radon-daughter samples are collected from various interior locations by ARIX and analyzed to identify any possible changes in air concentrations that could affect structure eligibility or priority. Such information is reported to the state for their evaluation.

In the case of structures other than residences, additiona 1 sampling is often accomplished at the discretion of ARIX. Since these structures are normally relatively large (e.g., warehouses) with highly variable use, and the state normally samples only one location within a structure, ARIX performs simultaneous radon/radon daughter sampling throughout the structure to identify gradients.

The UMTRAP radiological surveys are more detailed than those in GJRAP and include alpha and beta/gamma surface contamination measurements as well as soil sampiing and analysis for ${ }^{238} \mathrm{U}$ and ${ }^{226} \mathrm{Ra}$. The UMTRAP vicinity property "characterization" surveys are made by the inclusion survey contractor, ORNL, to determine if remedial action criteria (i.e., those promulgated by the EPA as a result of the Uranium Mill Tailings Radiation Control Act of 1978, Public Law 95-604) are 
exceeded. These include systematic outdoor surface gamma scans over the entire property with data averaged over $100-\mathrm{m}^{2}$ areas. At this point, if the criteria are exceeded, no additional measurements are made. If not, then systematic indoor surface gamma scans are performed and data are averaged by room to compare against the $20 \mathrm{R} / \mathrm{h}$ (above background) criteria. If neither of these sets of preliminary measurements indicates that the criteria are exceeded, then more extensive surveys (e.g., ${ }^{226}$ Ra in surface and subsurface soils, indoor alpha surface contamination and/or radon daughter concentrations) are conducted to determine whether criteria values for these parameters are exceeded.

Comprehensive radiological surveys are conducted during the engineering/construction phase. These are defined as radiological assessments in the Vicinity Property Management and Implementation Manual (VPMIM), UMTRA-DOE/ AL-050601 (DOE 1984a). These radiological (and engineering) assessments are performed to:

- outline the areal and volumetric extent of contamination on UATRAP vicinity properties

- determine if radon daughter concentration or gamma radiation exceed EPA standards

- document justification for applying EPA Supplemental ${ }^{\text {(a) }}$ Standards.

Specific radiological assessment measurements, made by the Inclusion Survey Contractor (ORNL) and the Technical Assistance Contractor (Jacobs-Weston) to define the extent of contamination on vicinity properties, include the following:

(a) Supplemental Standards can be applied when tailings exist in one or more of the following locations: under public thoroughfares, as a constituent in concrete or asphalt, as a foundation for public statues or monuments, or as a base for hard-surface public roads or railroad berms. 
- gamma surveys, indoors and out

- surface and subsurface soil sampling

- borehole logging

- grab-air sampling to determine radon and radon daughter concentrations in occupied or habitable buildings

- alpha and beta-gamma surveys to determine fixed and-removable contamination in structures.

The gamma surveys are performed on a grid system (maximum spacing of $100 \mathrm{ft}$ outdoors and $25 \mathrm{ft}$ indoors) at the surface and at $1 \mathrm{~m}$ above the surface; outdoor and indoor scans of the entire property are al so conducted. Soil samples are collected at so-called "biased" locations (with high gamma readings) on the surface (0 to $15 \mathrm{~cm}$ ) and in $15-\mathrm{cm}$ thick subsurface layers. The radon and radon daughter samples are typically five-minute grab air-samples within the most used portions of structures, the lowest structural levels (e.g., basements), or where there were high gamma readings or some other indication that the potential exists for elevated radon levels. In some special cases, longer-term radon daughter measurements are performed by ORNL or another remedial action support contractor, Mound Laboratory.

One additional item covered in the September, 1983, Summary Protocol UMTRAP Vicinity Properties, Identification - Characterization Inclusion Report (later included as part of Appendix A of VPMIM) is the definition of adequate background measurements. A minimum of 30 measurements are required in a selected nearby area where the coefficient of variation is less than or equal to $30 \%$. This is particularly important for UMTRAP surveys because the EPA external gamma radiation criteria are based on indoor radiation levels above background.

\section{FUSRAP Survey Protocols}

The FUSRAP survey programs were initiated to determine the radioiogical status of properties no longer being used by DOE or its predecessor organizations, Energy Research and Development Administration 
(ERDA), AEC, or Manhattan Engineering District (MED). Most of these properties were decontaminated in preparation for retirement from active use and are now being reevaluated, either for potential public sale or for possible reuse in a nonnuclear or other nuclear (e.g., use of different radionuciides) mode. In general, the FUSFAP sites are no longer the property of DOE.

A comprehensive radiological assessment of individual sites was initiated in 1974 by the AEC to determine if contamination remaining as a result of former MED/AEC work involving radioactive materials might require remedial action. The surveys were conducted primarily by Argonne National Laboratory, Los Alamos National Laboratory, and ORNL. The surveys were conducted with direct instrument measurements, as we11 as smears and air samples taken within the structures. Outdoor instrument surveys and soil and water sampling (as appiicable) were also conducted. The FUSRAP surveys, like the GJRAP and UMTRAP surveys, were conducted primarily to determine the presence or absence of contamination. However, there are differences in the methods employed to collect the data; for example, differences in grid size (spacing between measurements) or the absence of any use of a grid system, the minimum sensitivity of the instruments used, and the types of data recorded by the survey teams. It is also common to compare the results obtained from these surveys with standards and guidelines in the same manner as GJRAP and UMTRAP survey data.

Specific property surveys for FUSRAP sites have included measurements of direct alpha and beta-gamma instrument readings of accessible floors and walls to a height of $2 \mathrm{~m}$, as well as a representative selection of accessible overhead structures such as ceilings, pipes, vents, and light fixtures; smear samples of the accessible surfaces monitored during the direct radiation surveys; external gamma radiation levels within structures; indoor air samples for determining radon and radon daughters and the presence of any long-lived radioactive at,mospheric particles; external gamma radiation on and near the site; 
beta-gamma radiation at the surface in the most contaminated areas; radium and uranium concentrations in the soil; concentrations of radium, uranium, and thorium in water samples collected from drainage areas; and radium concentrations in mud samples taken from the drainage areas.

Operation of the FUSRAP survey program is based on the Formerly Utilized Sites Remedial Action Program Summary Protocol, Identification - Characterization - Designation - Remedial Action - Certification (DOE 1984b) document and the FUSRAP appraisal overview briefing package provided to the 00S Appraisal Team (August 1984) by Bechtel National (the FUSRAP Project Management Contractor). Other survey documents reviewed included the older set of FUSRAP survey reports entitied "Radiological Survey of the ... (name of site, city, state)" issued by DOE from 1977 to the present, numbered DOE/EV-0005/XX (1-50); the unnumbered "Comprehensive Radiological Survey ... (property name, city, state)" by ORAU for DOE; and the more recent "Survey Plan for the Radiological Characterization of ... (site name)" by Bechtel.

These comprehensive characterization surveys are to develop an adequate data base for engineering the design of the remedial action. The surveys include structures (surface contamination, exposure rate of the surface and at $1 \mathrm{~m}$, radon and thoron); ambient radiation (near surface gamma, surface beta-gamma, ganma exposure rate at $1 \mathrm{~m}$ ); soil (surface and subsurface samples, borehole gamma logging, radon emanation rates, and sediment samples); and water (surface and subsurface) samples.

A summary of the outdoor and indoor survey protocols at vicinity properties in DOE's Remedial Action Programs is presented in Tables 6.1 and 6.2. These tables provide a capsule summary of the various instrument surveys and sampling programs. Although differences in measurements and samples can be noted, those differences do not necessarily reflect on the adequacy of the different measurement protocols but may be the result of differing program objectives. 
TABLE 6.1 Summary of Outdoor Radiological Survey Protocois in DOE's Remedial Action Programs.

\begin{tabular}{|c|c|c|c|}
\hline Survey Mode & $\operatorname{GJRAP}(a)$ & UMTRAP(b) & FUSRAP (c) \\
\hline FIELD MEASUREMENT & & & \\
\hline $\begin{array}{l}\text { Gamma } \\
\text { surface } \\
1 \mathrm{~m} \\
\text { differential }\end{array}$ & $\begin{array}{l}X(d) \\
x \\
x(e)\end{array}$ & $\begin{array}{l}X \\
X\end{array}$ & $\begin{array}{l}X \\
X\end{array}$ \\
\hline $\begin{array}{l}\text { Beta } \\
\text { in situ } \\
\text { fixed }\end{array}$ & & $x$ & $x$ \\
\hline In situ soil & & & $x$ \\
\hline Borehole logging & & $x$ & $x$ \\
\hline SAMPLE ANALYSIS & & & \\
\hline $\begin{array}{l}\text { Soil } \\
\text { surface } \\
\text { subsurface }\end{array}$ & & $\begin{array}{l}x \\
x\end{array}$ & $\begin{array}{l}x \\
x\end{array}$ \\
\hline $\begin{array}{l}\text { Water } \\
\text { surface, grab } \\
\text { ground, grab }\end{array}$ & & & $\begin{array}{l}X \\
X\end{array}$ \\
\hline Sediment & & & $x$ \\
\hline
\end{tabular}

\footnotetext{
(a) ARIX 1983.

(b) DOE 1984a.

(c) DOE 1984b.

(d) $X$ indicates use of the survey mode.

(e) Place a lead shield beneath detector, observe the meter reading, remove the lead shield, observe a second meter reading, and record the difference.
} 
Table 6.2 Summary of Indoor Radiological Survey Protocols in DOE's Remedial Action Programs

Survey Mode

FIELD MEASUREMENT

$$
\begin{aligned}
& \text { Garma } \\
& \text { surface } \\
& 1 \text { meter }
\end{aligned}
$$

Beta

in situ

fixed

removable

Alpha

fixed

removable

SAMPLE ANALYSIS

Radon, grab

Radon daughters, grab

Air particulates
GJRAP(a)

$x$
$x$

$x$

$x$
$x$

$x$

$x$

$\begin{array}{ll}x & x \\ x & x\end{array}$

$\begin{array}{ll}x & X \\ x & X\end{array}$

$x(e)$

$x(d)$

$x(f)$

$x$

$x$

$x$

(a) ARIX 1983.

(b) DOE 1984a.

(c) DOE 1984b.

(d) Integrated radon measurements are also made at some locations.

(e) Single location considered to result in highest WL.

(f) Radon measurements are made at all vicinity properties, but radon daughters only at selected properties, not necessarily concurrent with or at same locations as grab radon samples. 
SURVEY DATA AND RISK ASSESSMENTS

The radiological measurements most useful for estimating health effects at sites contaminated with uranium mill tailings (i.e., UMTRAP and GJRAP) include: (1) interior and exterior measurements of gamma exposure rates due to the presence of tailings in the soil; (2) measurements of indoor radon daughter air concentrations; and (3) measurements of ${ }^{226} \mathrm{Ra}$ concentrations in soil and/or foodstuffs. Additional radiological measurements of value for FUSRAP include: (1) particulate radionuclide concentrations in air; and (2) other radionuclide concentration measurements in soil, water, and/or foodstuffs, as applicable on a site-specific basis.

Gama radiation measurements at a distance of $1 \mathrm{~m}$ above the ground (or floor surfaces) provide data for estimating whole-body doses due to external radiation. Measurements made at grid points, both outdoors and within structures, on contaminated properties provide excellent data for averaging the ambient gamma levels for the estimation of health effects due to gamma-ray exposure.

Radon daughter concentrations in air are often the most important factor in estimating heaith risks from uranium mill tailings. However, in contrast to the relative ease of measuring ganma radiation levels, radon daughters pose great problems in obtaining representative measurement values. The considerable variability of radon gas and radon daughter concentrations in air becomes apparent when examining measurements obtained with recording instruments over a period of a few days. It is not uncommon to find more than an order of magnitude difference between the maximum and minimum for a 24-hour period. At a given indoor measurement location, the radon daughter concentration may be affected by seasonal and diurnal variation in the radon exhalation rate from the underlying soil; outdoor weather conditions, principally high wind speeds; and changing ventilation rates due to the operation of heating or air conditioning units or the opening and closing of doors and windows. These factors make the use of integrated or continuous measurement equipment imperative. 
The other important factor in long-term radon daughter measurements is the possible range of differences from the annual mean, for a worker in a commercial or industrial facility or for a resident in a house. Usual daytime workers, for example, may be spared the buildup of radon daughters during the night so that the mean of the integrated measurement may be high for them, whereas occupants of a residence may have the bulk of their exposure during the evening and nighttime hours when radon daughter levels are at their peak. Keeping windows open or closed during the night may also make a substantial difference in the individual's radon daughter exposure. Because of these several factors that determine variability in radon and radon daughter concentrations in air, grab samples are not the most useful for health effects estimation.

Radon gas concentration measurements can be substituted for daughter measurements if the latter are not available. In order to convert radon gas to daughter concentration, it is necessary to provide values for the equilibrium factor. This introduces an additional element of uncertainty, which is best avoided by measuring the daughter concentrations directly. Beyond this, the most accurate assessment of the risk from radon daughters would additionally include information on the percentage of unattachment of RaA, the first daughter. In the absence of these data, reasonable values for the unattached activity can be assumed for most environmental and occupational exposure situations.

In addition to the relatively direct exposures due to gamma and radon daughters, other environmental exposure pathways must also be considered. Calculation of the order of magnitude of such exposures may be required in order to judge whether their contribution to health effects is sufficient to warrant in-depth investigation. Potential exposure pathways relevant to this discussion include inhalation of radioactive particles resulting from soil resuspension, ingestion of radionuclides that may take place through either agricultural use of iand or the growing of edible plants in home gardens, or ingestion of contaminated ground water as a result of transport of radionuclides in the soil into aquifers that may either be tapped by wells on the property or, if open, may drain into surface streams that serve as a drinking water source. 
Soil concentrations of ${ }^{239} \mathrm{Pu},{ }^{238} \mathrm{U},{ }^{226} \mathrm{Ra},{ }^{60} \mathrm{Co}$, and, if present, other radionuclides are obtained primarily to map out the residual contaminants in a given location with respect to lateral extension and depth. This information is essential to the calculation of the location and volume of soil to be removed in the event that such removal is included in a remedial action plan. These measurements also provide data relevant to the estimation of the impacts of environmental exposure pathways to man, which can be useful in estimating health effects. Elevated radionuclide concentrations in soiT at specific locations may also indicate the need for additional survey data, such as radon daughter measurements in structures and additional sampling and analyses for suspected contaminants in water.

\section{RECOMMENDATIONS AND CONCLUSIONS}

The close scrutiny of radiological survey data from DOE's Remedial Action Programs has provided an opportunity to evaluate the effectiveness of the measurement schemes that are in current use. Insofar as one purpose of the radiological surveys conducted by DOE contractors is the identification of actual or potential health hazards, the adequacy of their data for health effects estimation becomes an essential concern. For the purpose of this study, inadequacies have been identified and changes recommended in the measurement protocols litilized by the radiological survey contractors. Improvement in the design of measurement sampling schemes will increase the accuracy of the health-risk estimates and can mitigate the need for any measurements in addition to 
those that were made originally at any site. Thus, if generic inadequacies are identified and corrected, the cost of the program will be reduced and the quality of estimates improved.

The most significant weakness in existing sampling techniques from a risk assessment standpoint is the 1ack of long-term radon/radon daughter concentration measurements. Although this was recognized and implemented early in the GJRAP, all other DOE remedial action survey programs have not followed suit.

The following suggestions for the revision of current radiological survey procedures and for the acquisition of more detailed property occupancy data are offered to improve the quality of health-effects estimates for vicinity properties in the DOE Remedial Action Programs. In offering these suggestions, we recognize that the acquisition of new data may be 1 imited by budgetary considerations. However, in some cases the desired objectives may be achieved by substituting new for present procedures or the simple recording of accessory information.

The need for improved occupancy data has been mentioned already. Our intent is not to fix precisely the present occupancy pattern, but rather to identify the typical annual-equivalent occupancy pattern of an "as is" property with respect to the number of occupants and their locations. This might require modification of the existing pattern. For example, if a single person lives in a three-bedroom house, a preferred occupancy might be four or five persons. If a business in a commercial property grossiy under-or overutilizes space, appropriate adjustments could be made in the occupancy number. An estimate of present occupancy is frequently sufficiently representative to obviate the need for any adjustment. The important need is for a reliable total occupancy number with a representative distribution of the occupants within a building. This is especially true for areas in a structure having differing radiation exposure levels.

Our suggestions for improved radon gas and/or daughter measurements concern the timing and the type of measurements. When grab radon gas 
and daughter measurements are the only ones available, they should be done simultaneously and in areas of probable differing daughter concentrations to allow calculation of the respective equilibrium factors. This is especially true for all properties where radon daughter levels are likely to be elevated with respect to background. It is also desirable to do the measurements under conditions that are representative of the typical use of a room or area within a structure. For example, a room that is closed most of the time should not be sampled when the door is open. Conversely, it would be inappropriate to obtain measurements after a lengthy closed period in an area such as a garage or warehouse if the customary use calis for open doors.

Where working levels are above background, at least one long-term measurement should be made in a building to compensate for the inherent instability of grab sample measurements. For example, placing inexpensive track-etch or passive environmental radon monitor (PERM) devices in several areas in a building for simultaneous gas measurements might be considered as an alternative to more expensive survey methods. The purpose would be to define the relative levels of radon gas concentrations in different areas in a building. The combination of a reliable continuous or integrated radon gas or, if available, daughter measurement, and track-etch gas measurements at the same and other locations in a building would permit adjustment of the (presumably reliable) integrated measurement value for other areas within the structure. Then, radon daughter values can be estimated for those areas by using appropriate estimates of the local equitibrium factor.

Background values for radon and radon daughters should be based on measurements representative of the area being characterized. Supplemental background measurements could be obtained by placing instruments in nearby uncontaminated homes or commercial properties.

The above suggestions are offered to provide a basis for discussion. We believe that the occupancy data should be both reliable and more detailed. If possible, the radon gas and daughter measurements should be performed such that they yield representative equilibrium 
factors, a reliable long-term radon gas or daughter measurement somewhere in a structure, and a basis for deriving radon daughter concentrations at other areas in the structure. These objectives may be accomplished by the use of distributed, relatively inexpensive measurement devices. Such a program will allow the calculation of projected health effects for persons occupying different areas in a building on the basis of direct or derived values for radon daughter exposures for those particular areas.

\section{REFERENCES}

ARIX 1983. Procedures Manual for Grand Junction Remedial Action Program, ARIX Corporation and The Colorado Department of Health, Denver, Colorado.

DOE 1984a. Vicinity Property Management and Implementation Manual, UMTRA-DOE/AL-050601, U.S. Department of Energy, Albuquerque, New Mexico.

DOE 1984b. Formerly Utilized Sites Remedial Action Program Summary Protocol, Identification - Characterization - Designation - Remedial Action-Certification, U.S. Department of Energy, Washington, D.C. 
SUPPLEMENTAL BIBLIOGRAPHY

OAK RIDGE NATIONAL LABORATORY SURVEY REPORTS

Document No.

$$
\text { ORINL-5448 }
$$

ORNL-5451

ORNL-5453

ORNL-5454

ORNL-5455

ORNL-5456

ORNL -5457

ORNL -5458

ORNL. -5459

ORNL -5460

ORNL-5461

ORNL -5462

ORNL -5465

DRNL -5489
Title

Assessment of the Radiological Impact of the Inactive Uranium-Mill Tailings at Mexican Hat, Utah

Radiological Survey of the Inactive UraniumMitl Tailings at Durango, Colorado

Radiological Survey of the Inactive UraniumMill Tailings at Gunnison, Colorado

Radiological Survey of the Inactive UraniumMill Tailings at Naturita, Colorado

Radiological Survey of the Inactive UraniumMill Tailings at Rifle, Colorado

Radiological Survey of the Inactive UraniumMill Tailings at Maybe11, Colorado

Assessment of the Radiological Impact of the Inactive Uranium Mill Tailings at Grand Junction, Colorado

Radiological Survey of the Inactive UraniumMill Tailings at Ambrosia Lake, New Mexico

Radiological Survey of the Inactive UraniumMill Tailings at Green River, Utah

Radiological Survey of the Inactive UraniumMill Tailings at the Spook Site, Converse County, Wyoming

Radiological Survey of the Inactive UraniumMill Tailings at Riverton, Wyoming

Radiological Survey of the Inactive UraniumMill Tailings at Falls City, Texas

Radiological Survey of the Radioactive Sands and Residues at Lowman, Idahe

Radon and Radon-Daughter Measurements At and Near the Former Middlesex Sampling Plant, Middlesex, New Jersey
Year

1980

1980

1980

1980

1980

1980

1980

1980

1980

1980

1980

1980

1980

1980 
FUSRAP SURVEY REPORTS

Document No.

Title

Year

DOE/EV $-0005 / 01$

Radiological Surveys of Properties in the Middlesex, New Jersey Area

1981

DOE/EV-0005/02 Formerly Utilized MED/AEC Sites Remedial

Action Program Radiological Survey of the

1977

Hooker Chemical Company, Niagara Falis,

New York

00E/EV-0005/04 Fomeriy Utilized MED/AEC Sites Remedial

Action Program Radiological Survey of the

1978

Ashland 0if Company (Formerly Haist

Property)

DOE/EV-0005/05 Radiological Survey of the Former Linde

Uranium Refinery

1978

DOE/EV-0005/06 Fomerly Utilized MED/AEC Sites Remedial

Action Program Radiological Survey of the

Seaway Industrial Park

D0E/EV-0005/08 Formerly Utilized MED/AEC Sites Remedial Action Program Radiological Surveys of the

1978

E.I. Dupont DeNemours and Company, Deepwater, New Jersey

DOE/EV-0005/10 Formerly Utilized MED/AEC Sites Remediai

Action Program Radiological Survey of the

1979 Former Horizons Incorporated, Metal Handling Facility, Cleveland, Ohio

D0E/EV-0005/11 Formerty Utilized IIED/AEC Sites Remedial Action Program Radiological Survey of the St. Louis Airport Storage Site, St. Louis, Missouri

DOE/EV-0005/12 Formerly Utilized MED/AEC Sites Remedia? Action Program Radiological Survey of the Pennsylvania Railroad Landfil? Site, Burrell Township, Pennsylvania

D0E/EV-D005/13 Formerly Utilized MED/AEC Sites Remedial Action Program Radiological Survey of the Museum of Science and Industry, 57 th St. and Lake Shore Drive, Chicago, Illinois

D0E/EV-0005/14 Formerly Utilized MED/AEC Sites Remedial Action Program: Radiological Survey of the Bayo Canyon, Los Alamos, New Mexico - Final Report 
DOE/EV-0005/17 Formerly Utilized MED/AEC Sites Remedial

Formerly Utilized MED/AEC Sites Remediál

Action Program Radiological Survey of the

Former Virginia-Carolina Corporation

Uranium Recovery Pilot Plant, Nicholas,

Florida

DOE/EV-0005/19 Formerly Utilized MED/AEC Sites Remedial

Action Program Radiological Survey for the Building Site 421, United States Watertown Arsena 1

DOE/EV-0005/20

Radiological Survey of the Middlesex

Municipa? Landfill

D0E/EV-0005/2l Radiological Survey of the Former Uranium Recovery Pilot and Process Sites, Gardinier Incorporated, Tampa, Florida

DOE/EV-0005/27 Radiological Survey of the Mallinckrodt Chemical Works, St. Louis, Missouri

DOE/EV-0005/28 Radiological Survey of the Former Bridgport Brass Company Special Metals Extrusion Plant, Adrian, Michigan

1980

1980

1981

DOE/EV-0005/29 Radiological Survey of the Former Kellex Research Facility

DOE/EV-0005/30 FUSRAP MED/AEC Radiological Survey of Site of a Former Radioactive Liquid Waste Treatment Plant (TA-45) and Effluent Receiving Areas of Acid, Pueblo, and Los Alamos

DOE/EV-0005/31 Radiological Survey of the Shpack Landfill Norton, Massachusetts 
$\frac{\text { Document No. }}{\text { DOE/OR/20722-10 }}$

DOE/OR/20722-12 Radiological Survey Report for the Residen-
tial Property at 14 Peck Avenue, Pompton plains

D0E/OR/20722-13 Radiological Survey Report for the Residential Property at 17 Peck Avenue, Pompton Plains

DOE/OR/20722-31 Radiological Survey Report for the Residential Property

DOE/OR/20722-32 Radiological Survey Report for the Residential Property at 86 Park Way

DOE/0R/20722-33 Radiological Survey Report for the Residential Property at 90 Park Way

D0E/OR/20722-34 Radiological Survey Report for the Residential Property at 10 Grove Avenue

DOE /OR/20722-35

Radiological Survey Report for the Residential Property at 14 Grove Avenue

$\mathrm{DOE} / 0 \mathrm{R} / 2 \mathrm{D} 722-36$

Radiological Survey Report for the Residential Property at 18 Grove Avenue

DOE/OR/20722-37 Radiological Survey Report for the Residential Property at 22 Grove Avenue

$\mathrm{DOE} / \mathrm{OR} / 20722-38$

Radiological Survey Report for the Residential Property at 26 Grove Avenue

DOE/OR/20722-39

DOE / OR/20722-4D

DOE /OR/20722-41

DOE $/ 0 R / 20722-42$

$\mathrm{DOE} / 0 \mathrm{R} / 2 \mathrm{D} 722-43$

$\mathrm{DOE} / 0 \mathrm{R} / 20722-44$
Radiological Survey Report for the Residential Property at 30 Grove Avenue

Radiological Survey Report for the Residential Property at 34 Grove Avenue

Radiological Survey Report for the Residential Property at 38 Grove Avenue

Radiological Survey Report for the Residential Property at 42 Grove Avenue

Radiological Survey Report for the Residential Property at 46 Grove Avenue

Radiological Survey Report for the Residential Property at 50 Grove Avenue
Year

1984

1984

1984

1984

1984

1984

1984

1984

1984

1984

1984

1984

1984

1984

1984

1984

1984 


\section{TECHNICAL MEASUREMENTS CENTER PUBLICATIONŚ}

Document NNo.

GJ/TMC-02

GJ/TMC -03

GJ/TMC-04

GJ/TMC -06

GJ/TMC-08

GJ/TMC -14

GJ/TMC-16

GJ/TMC - 19
Title

Year

Review of Selected OOE Remedial Action Field Measurement Procedures for the Summer of 1982

Abbreviated Total-Count Logging Procedure for Use in Remedial Action

Evaluation of Methods for the Estimation of Indoor Radon Daughter Concentrations for Remedial Action Programs

Surface Gamma-Ray Measurement Protocol

1984

Procedures for the Collection and Preservation of Groundwater and Surface Water Samples and for the Instailation of Monitoring WeTls

Reconnaisance Stream-Sediment Sampling Procedures

Test and Evaluation of Selected Instruments for Surface Gamma-Ray Measurements

Laboratory Intercomparison of AnaTytical Results on Sampies Contaminated by UraniumMill Tailings 
UMTRAP VICINITY PROPERTY SURVEY REPORTS

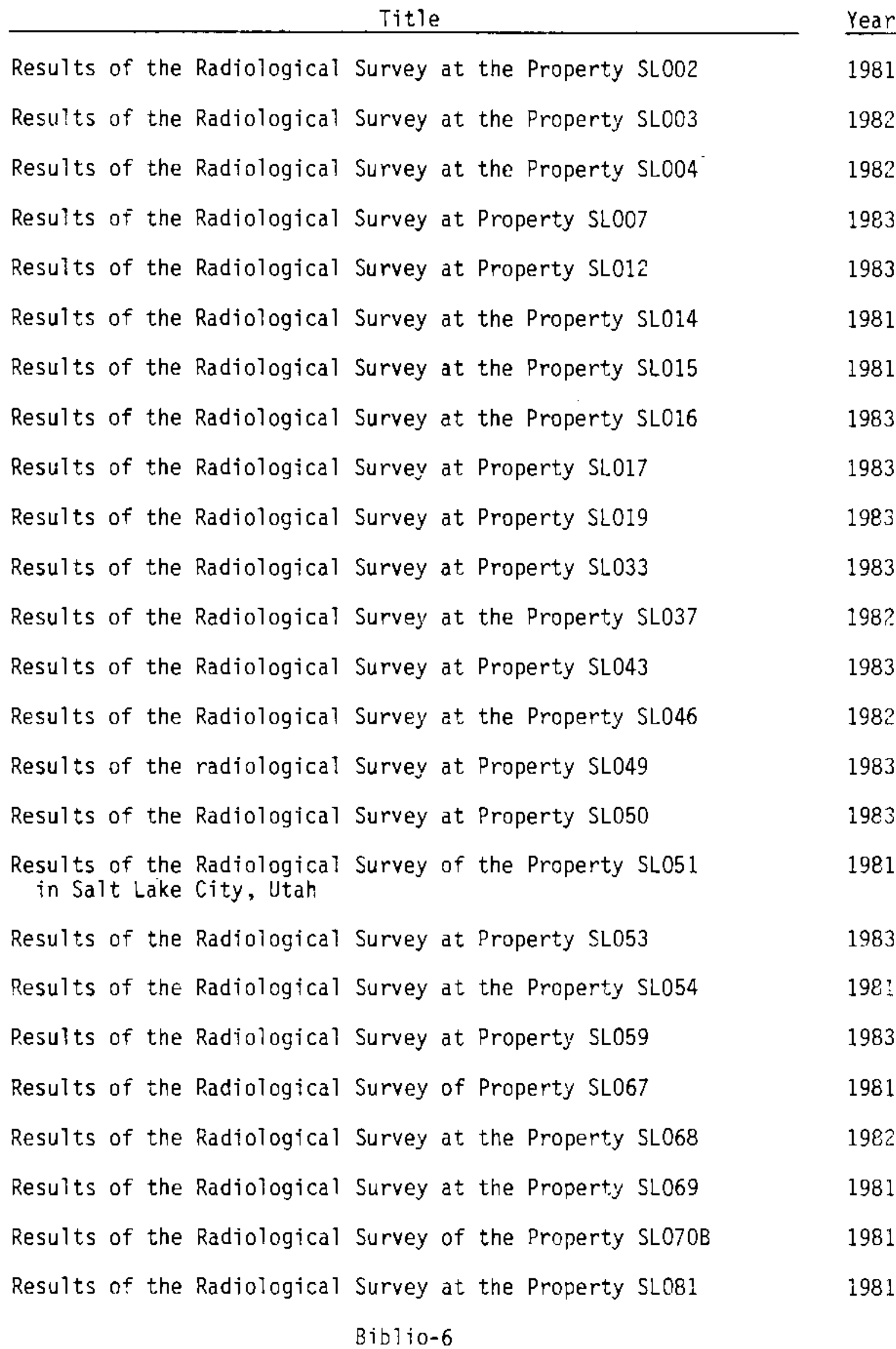


Results of the Radiological Survey at the Property SL082 1982

Results of the Radiological Survey at Property DU027 1983

Results of the Radiological Survey at Property DU038 1983 


\section{DISTRIBUTION}

No. of

Copies

OFFSITE

L. F. Anderson

Utah State Health Department

150 WN Temple

Salt Lake City, UT 84103

W. J. Arthur

Uranium Mill Tailings

Project Office

Department of Energy

5301 Central Avenue, N.E.

Suite 1700

Albuquerque, NM 87115

K. R. Baker

Jacobs Engineering Group, Inc.

5301 Centra? Avenue, N.E.

Suite 1700

Albuquerque, NM 87108

D. M. Ball

ATbuquerque Opns Office

Department of Energy

P. 0. Box 5400

Kirkland AFB

Albuquerque, NM 87115

L. BaTl

Grand Junction Area Office

Department of Energy

P. 0. Box 2567

Grand Junction, CO 81502

W. Barber

EH-13, GTN

Department of Energy

Washington, DC 20545

J. H. Barry

Operational Safety Division

Idaho Operations office

Department of Energy

550 Second Street

Idaho Falis, ID 83401
No. of

Copies

A. Battaglia

Centro Informazioni Studi

Esperienze

Via Reggis Emilie 39

20030 Segrate, C.P. 3986

Milan, ITALY

R. J. E. Baublitz

NE-24, GTN

Department of Energy

Washington, DC 20545

J. D. Berger

Oak Ridge Associated Universities

P. 0. Box 117

Oak Ridge, TN 37830

B. A. Berven

Dak Ridge National Laboratory

P. 0. Box $X$

Oak Ridge, TN 37831

L. C. Brazley, Jr.

NE-24, GTN

Department of Energy

Washington, DC 20545

M. E. Crew

Grand Junction Area Office

Department of Energy

P. 0. Box 2567

Grand Junction, CO 81502

1. M. Davies

Institute of Cancer Research

BT lock D

Clifton Avenue

Sutton, Surrey

ENGLAND SM2 5PX

J. T. Davis

Environment, Safety and Quality Assurance Division

San Francisco Operations Office

Department of Energy

1333 Broadway

0akland, CA 94612 
No. of

Copies

E. G. Delaney

$\mathrm{NE}-24, \mathrm{GTN}$

Department of Energy

Washington, DC 20545

G. P. Dix

26619 Haney Avenue

Damascus, MD 20750

J. R. Duray

Bendix Field Engineering Corp.

P. 0. 80x 1569

Grand Junction, CO 81502

K. F. Eckerman

Oak Ridge National Laboratory

P. 0. Box $X$

Oak Ridge, TN 37831

S. Elijott

Nevada Operations Office

Department of Energy

P. 0. Box 14100

Las Vegas, NV 89114

G. Frangos

EH-123, GTN

Department of Energy

Washington, DC 20545

Frances Fry

Environmental Monitoring Group

National Radiological Protection Board

Didcot, 0xon

ENGLAND OX11 ORQ

C. Garcia

Operational Safety Division

Albuquerque Operations Office

Department of Energy

P. 0. Box 5400

Atbuquerque, NM 87115

T. L. Gilbert

Environmentai Impact Studies

Department

Argonne National Laboratory

9700 S. Cass Avenue

Argonne, IL 60439
No. of

Copies

R. D. Glenn

Bechtel National, Inc.

P. 0. Box 350

Oak Ridge, TN 37830

D. H. Groel sema

NE-24, GTN

Department of Energy

Washington, DC 20545

R. J. Guimond

Office of Radiation Programs

Environmental Protection Agency

401 M Street, S.W.

Washington, DC 20460

W. R. Hansen

Los Alamos Nationa? Laboratory

MS $\mathrm{K}-490$

P. 0. 80x 1663

Los Alamos, NM 87545

Gerry A. Harte

Berkeley Nuclear Laboratories

Berkeley, Gloucestershire

ENGLAND GL13 9P8

J. W. Healy

51 Grand Canyon Drive

White Rock, NM 87544

P. Jenkins

Mound Facility

P. 0. Box 32

Miamisburg OH 45342

E. L. Keller

Oak Ridge Operations Dffice

Department of Energy

P. 0. Box E

Oak Ridge, TN 37830

A. F. Kluk

DP-122.1, GTN

Department of Energy

Washington, DC 20545 
No. of

Copies

S. Lichtman

Office of Radiation Programs

ANR-460

Environmental Protection Agency

401 is Street, S.W.

Washington, DC 20460

C. A. Little

Oak Ridge Associated Universities

$c / 0$ Department of Energy

P. 0. Box 2567

Grand Junction, CO 81502

A. D. Luck

Oak Ridge Associated Universities

P. 0. Box 2567

Grand Junction, CO 81502

P. Merry-Libby

Environmental Research Division

Argonne National Laboratory

9700 S. Cass Avenue

Argonne, IL $6043 \mathrm{~g}$

R. Moser

Operations and Environmenta]

Safety Division

Chicago Operations Office

Department of Energy

9800 S. Cass Avenue

Argonne, IL

W. E. Mott

EH-12, GTN

Department of Energy

Washington, OC 20545

T. S. Neede Ts

EH-123, GTN

Department of Energy

Washington, DC 20545

2 Park Owen

Remedial Action Program

Information Center

Department of Energy

P. 0. Box 62

Oak Ridge, TN 37830
No. of

Copies

\author{
D. E. Patterson \\ DP-226.1, GTN \\ Department of Energy \\ Washington, DC 20545 \\ J. Piechowski \\ CEA/CEN FAR/DPr-SPS \\ Fontenay-aux-Roses \\ BP6-G2-260 \\ Hauts de Seine \\ FRANCE
}

G. R. Ripley

Utah State Health Department

150 WN Temple

Salt Lake City UT 84103

G. Sciocchetti

Lab. Radiotossicologica

Rad. Pro.

CRE Casaccia

Cnen, CP 2400, I-00100

Roma, ITALY

D. R. Sheppard

EH-12, GTN

Department of Energy

Washington, DC 20545

J. Sinnaeve

CEC

Rue de la Loi

200, B-1049

Brussels

BLEGIUM

R. J. Stern

EH-15, FORS

Department of Energy

Washington, DC 20585

J. G. Themelis

Uranium Mill Tailings

Project Office

Department of Energy

5301 Central Avenue, N.E.

Suite 1700

Albuquerque, NM 87115 
No. of

Copies

J. E. Tili

Radiological Assessments Corporation

Rt. 2, Box 122

Neeses, SC 29107

Margot Tirmarche Department de Protection Centre d'Etudes Nucleaire BP No 6 92260 Fontenay-aux-Roses FRANCE

V. R. Veluri Occupational Health and Safety Division

Argonne National Laboratory 9700 S. Cass Avenue Argonne, IL 60439

A. Wallo The Aerospace Corporation 955 L'Enfant PIaza

Suite 4000

Washington, DC 20024

C. G. Welty, Jr.

EH-123, GTN

Department of Energy

Washington, DC 20545

M. G. White

Uranium Mill Tailings

Project office

Department of Energy

5301 Central Avenue, N.E.

Suite 1700

Albuquerque, NM 87115

A. J. Whitman

NE-24, GTN

Department of Energy

Washington, DC 20545
No. of

Copies

U. F. Wing

Oak Ridge Operations Office

Department of Energy

P. 0. Box E

Oak Ridge, TN 37830

30 Technical Information Center

ONSITE

5 DOE Richland Operations Office

K. W. Braken

K. R. Absher/P. K. Clark

C. E. Miller

D. R. Elle

J. D. White

3 UNC Nuclear Industries

R. N. Coy

T. E. Dabrowski

D. R. Steffes

47 Pacific Northwest Laboratory

W. J. Bair

J. B. Brown, Jr.

F. T. Cross (5)

D. H. Denham (5)

D. W. Dragnich

B. J. Kelman

W. E. Kennedy, Jr. (5)

S. Marks (10)

R. P. Marshall

0. R. Moss

B. A. Napier

R. G. Schreckhise/GF

J. K. Soldat

R. D. Stenner (5)

J. A. Stottlemyre

Publishing Coordination (2)

Technical Information (5) 